\author{
UNIVERSIDADE DE SÃO PAULO \\ FACULDADE DE MEDICINA DE RIBEIRÃO PRETO \\ DEPARTAMENTO DE PATOLOGIA E MEDICINA LEGAL
}

Fabiana Alves de Miranda

\title{
AVALIAÇÃO DA PROGRESSÃO TUMORAL DO CÂNCER DE LARINGE ASSOCIADA À INFECÇÃO PELO PAPILOMAVÍRUS HUMANO (HPV).
}

\begin{abstract}
Dissertação de Mestrado apresentada ao Departamento de Patologia e Medicina Legal da Faculdade de Medicina de Ribeirão Preto da Universidade de São Paulo para obtenção do Título de Mestre em Ciências Médicas. Opção: Patologia Experimental.
\end{abstract}

Ribeirão Preto 
Fabiana Alves de Miranda

\section{AVALIAÇÃO DA PROGRESSÃO TUMORAL DO CÂNCER DE LARINGE ASSOCIADA À INFECÇÃO PELO PAPILOMAVÍRUS HUMANO (HPV).}

Dissertação de Mestrado apresentada ao Departamento de Patologia e Medicina Legal da Faculdade de Medicina de Ribeirão Preto da Universidade de São Paulo para obtenção do Título de Mestre em Ciências Médicas. Opção: Patologia Experimental.

Orientador: Prof.Dr. Edson Garcia Soares

Ribeirão Preto 


\section{FICHA CATALOGRÁFICA}

\section{Miranda, Fabiana Alves}

Avaliação da progressão tumoral do câncer de laringe associada infecção pelo Papillomavírus Humano (HPV).

Ribeirão Preto, 2009.

112 p. : il. ; $30 \mathrm{~cm}$

Dissertação de Mestrado, apresentada à Faculdade de Medicina de Ribeirão Preto/ USP - Área de concentração: Patologia Experimental.

Orientador: Soares, Edson Garcia. 
Aos Amores da minha vida

A minha mãe, Maria Elísia por ser meu maior exemplo de mulher, meu porto seguro, por sua força e dedicação, por sempre estar ao meu lado mesmo que distante, apoiando e aconselhando, e pelo seu amor incondicional sem o qual eu não seria nada.

Ao meu padrasto Jair por estar sempre por perto e pelo amor dedicado.

Ao meu pai Sebastião (in memoriam) pelas lembranças alegres do tempo de criança.

Aos meus queridos e amados: irmão Fábio, cunhada Andreciliana e sobrinha Vitória, que apesar da distância sempre estão presente no amor no cuidado e no coração.

Ao meu amor Márcio, por sempre estar pertinho, cuidando, aconselhando, obrigada por tudo que compartilhamos e vivemos juntos. 
AGRADECIMENTOS 
À Deus e Jesus Cristo, por me amarem e me concederem a vitória.

Ao Prof. Dr. Edson Garcia Soares pela confiança estabelecida a mim, por ser tornar um amigo nesta jornada, pela orientação e apoio ao meu crescimento científico.

À Profa. Dra. Christiane Pienna Soares, pela amizade, atenção sempre e apoio científico.

Ao Prof. Dr. Celso Mendes Teixeira Júnior, pela atenção e auxílio na análise estatística

Ao Prof. Dr. Antônio Donadi, por ter concedido o laboratório de Imunologia Molecular para a realização das técnicas de biologia molecular.

Ao Prof. Dr. Aguinaldo Simões, por ter cedido seu laboratório para a realização da técnica de extração de DNA.

À amiga Ana Maria da Rocha, pela amizade, conselhos preciosos, dedicação e zelo e pelo apoio técnico.

Às queridas amigas Márcia Cristina Guimarães Preti, Renata Toscano Simões, Régia Caroline Peixoto Lira, Marcela Kazue Hassumi e Társia Giabardo Alves Silva pela amizade e colaboração.

Aos amigos de laboratório Mariana Machado, Emília Jalil, Gustavo Martelli e João Alexandre Pancoto pela amizade e companheirismo.

Aos amigos pós-graduandos da Patologia, Patrícia Modiano, Aline Turati, Karina da Mata e Cleverson Rodrigues pelo apoio e companheirismo.

As amigas técnicas Neife Deghaide e Sandra Rodrigues pela amizade e companheirismo nos dias árduos de laboratório. 
Aos funcionários do Arquivo do Departamento de Patologia Décio A. Barrionovo Filho e César Alberto Brigato Jr. pelo auxílio e colaboração.

Ao Comitê de Ética em Pesquisa do Hospital das Clínicas da Faculdade de Medicina de Ribeirão Preto pelo apoio e aprovação deste trabalho.

Ao CNPQ, CAPES, FAPESP e FAEPA pelo auxílio científico e financeiro.

Á todos que contribuíram para a realização deste trabalho de maneira direta ou indireta:

Neide Terezinha Gonçalves

Rosângela M. Castania de Paiva

Camila de Luca Zambonini

Edna Pio Silva (in memoriam)

Antônio de Pádua Martins

Deise Lúcia Chesca Simões

Deisy Mara Silva

Rosângela Orladim 
"Sem sonhos, as perdas se tornam insuportáveis, as pedras do caminho se tornam montanhas, os fracassos se tornam golpes fatais. Mas, se você tiver grandes sonhos... seus erros produzirão crescimento, seus desejos produzirão oportunidades, e seus medos produzirão coragem..." 
MIRANDA, F.A. Avaliação da progressão tumoral do câncer de laringe associada à infecção pelo Papilomavírus Humano (HPV). 2009. 112p. Dissertação (Mestrado em Patologia Experimental) - Faculdade de Medicina de Ribeirão Preto, Universidade de São Paulo, Ribeirão Preto.

Para que ocorra a transição do epitélio normal de laringe para carcinoma escamoso é necessário um processo de múltiplas etapas tal como exposição prolongada ao fumo e álcool e uma possível associação à infecção pelo HPV. Vários tipos de marcadores moleculares vêm sendo estudados na carcinogênese da laringe, entre eles proteínas associadas a apoptose (bcl-2 e PARP-1) assim como proteínas envolvidas em múltiplos processos biológicos como a Galectina-3. Neste estudo foram realizadas análise imunoistoquímica quantitativa e qualitativa para bcl-2, PARP-1 e galectina-3 em 65 pacientes diagnosticados com câncer de laringe subdivididos em: carcinoma de laringe in situ (CLIS), carcinoma de laringe com metástase (CLM), sem metástase (CLS) e linfonodos cervicais (LC). A detecção e tipificação do HPV foram realizadas pela reação em cadeia da polimerase (PCR) e os tipos de HPV avaliados foram HPV 6, 11, 16, 18, 31 e 33. Na avaliação quantitativa de galectina-3 observou-se um significativo aumento de expressão no carcinoma invasivo de laringe (CLS e CLM) quando comparado com carcinoma in situ (CLIS), podendo concluir que essa proteína seria um bom marcador pra progressão de câncer de laringe. Para as proteínas PARP-1 e bcl-2 não houve diferença nos níveis de expressão nos grupos analisados. $\mathrm{Na}$ análise qualitativa PARP-1 apresentou uma homogeneidade de marcação tanto alta como baixa entre os grupos. Em relação à Galectina-3 observou-se um predomínio de casos com alta expressão, diferentemente da proteína bcl-2 onde o predomínio foi de baixa expressão em todos os casos de carcinoma de laringe e seus respectivos linfonodos metastáticos. Dos 65 pacientes, $55(84,6 \%)$, foram positivos para beta-globina e 7 (12.7\%) dos 55 pacientes foram positivos para HPV. Não foi possível verificar quaisquer correlações entre as proteínas Galectina-3, bcl-2 e PARP-1 e o HPV devido ao baixo índice de casos positivos.

Palavras-chave: bcl-2, PARP-1, Galectina-3, HPV, carcinoma de laringe, imunoistoquímica, PCR 
MIRANDA, F.A. Evaluation of tumor progression in laryngeal carcinoma associated with human Papilomavirus (HPV) infection 2009. 112p. Dissertation (Mastery in Experimental Pathology) - Faculty of Medicine of Ribeirão Preto, University of São Paulo, Ribeirão Preto.

To occur the transition from normal epithelium to squamous cell carcinoma is a necessary a for multiple stages process, such as smoking and alcohol abuse and a possible association with HPV infection. Several types of molecular markers have been studied in cancer of larynx, including proteins associated with apoptosis (bcl-2 and PARP-1) and proteins involved in many biological process such as galectin-3. In this study, analyses of qualitative and quantitative immunohistochemistry was performed for bcl-2, PARP-1 and galectin-3 in 65 patients diagnosed with laryngeal squamous cell carcinoma divided into in situ laryngeal carcinomas $\left(\mathrm{LSCC}^{\mathrm{S}}\right)$, laryngeal squamols cells carcinomas without metastases $\left(\mathrm{LSCC}^{\mathrm{WT}}\right)$ and with metastasis $\left(\mathrm{LSCC}^{\mathrm{W}}\right)$ and cervical lymph nodes (CL). HPV detection and typing was performed by PCR and the HPV types evaluated were HPV 6, 11, 16, 18, 31 and 33. In quantitative of galectin-3 there was observed a significant increase of expression in invasive laryngeal squamous cell carcinoma $\left(\mathrm{LSCC}^{\mathrm{WT}}\right.$ and $\mathrm{LSCC}^{\mathrm{W}}$ ) compared with in situ laryngeal carcinomas $\left(\mathrm{LSCC}^{\mathrm{S}}\right)$, may indicating that this protein could be a good marker for progression of laryngeal carcinoma. For PARP-1 and bcl-2 protein there was no difference in the levels of expression in all groups studied. In qualitative analysis PARP-1 showed a homogenous immunolabeling in both high and low among the groups. In relation to Galectin-3, it was observed a predominance of cases with high expression, unlike the protein bcl-2 where the expression prevalence was low in all cases of laryngeal carcinoma and their metastatic lymph nodes. Of the 65 patients, 55 (84.6\%) were positive for beta-globin and 7 (12.7\%) of 55 patients were positive for HPV. Because of a low incidence of HPV in the cases studied, it was not possible correlate the proteins bcl-2, PARP-1 and Galectin-3 with the presence of HPV.

Key Words: bcl-2, PARP-1, Galectin-3, HPV, laryngeal carcinoma, immunohistochemistry, PCR 


\subsection{O CÂNCER DE LARINGE}

Anualmente, mais de 900.000 pessoas recebem o diagnóstico de câncer de cabeça e pescoço (Chin, Boyle et al., 2006), e aproximadamente 350.000 pacientes morrem desta doença (Ferlay, 2001). Devido a estes números, este tipo de câncer é considerado o sexto mais comum no mundo (St John, Abemayor et al., 2006). O termo câncer de cabeça e pescoço é representado por neoplasias malignas que acometem as regiões da cavidade oral, faringe e laringe, sendo este último o mais comum, representando cerca de $25 \%$ dos tumores malignos que acometem esta área e $2 \%$ de todas as doenças malignas. Aproximadamente, $2 / 3$ desses tumores surgem na corda vocal verdadeira e 1/3 acomete a laringe supra-glótica (INCA 2008).

No mundo, estima-se um total de 159.000 novos casos de câncer de laringe a cada ano, sendo mais comum no sexo masculino numa prevalência de 7:1. (Parkin, Bray et al., 2001). Na Europa, Ferlay e colaboradores estimaram para ano de 2006 mais de 42.100 novos casos de câncer de laringe entre homens e 3.800 casos entre mulheres, e destes, 19.200 homens e 1.800 mulheres irão a óbito em decorrência da doença. Este tipo de tumor é raro em pacientes jovens, envolvendo apenas 4-6\% de indivíduos com menos de 40 anos. Entre a população masculina européia, a incidência de câncer de laringe aumenta com a idade, com a maior parte dos carcinomas sendo diagnosticados em indivíduos com 65 anos ou mais (cerca de $45 \%$ de todos os casos), e um pico de incidência na sexta e sétima décadas com cerca de 50 novos casos por ano para cada 100.000 indivíduos (Ferlay, 2001). 
No Brasil, segundo o Instituto Nacional do Câncer (Brasil, 2008), as regiões sudeste, sul e centro-oeste do Brasil são as mais afetadas, apresentando em 1995 e 1999, uma variação de incidência de $1,30 \%$ e taxa média de mortalidade de $2,21 \%$ por 100.000 habitantes. Em relação à etnia e urbanização, estudos em diversos países demonstram uma alta incidência de câncer de laringe, respectivamente, entre negros e em áreas urbanas (Levi, La Vecchia et al., 1993; Muir e Weiland, 1995; Parker, Tong et al., 1996). Quanto à faixa etária, o pico de incidência do câncer de laringe é em torno de 60 a 70 anos, predominante no sexo masculino (Filho, 2004).

Dentre os tipos de lesão encontrados no tecido laríngeo, o carcinoma espinocelular é o mais freqüente no Estado de São Paulo, com 93,7\% de incidência em relação aos demais tipos de tumores encontrados nessa região (Filho, 2004).

Há uma marcante heterogeneidade do desenvolvimento e agravamento do câncer de laringe entre as regiões geográficas, não só nas brasileiras como no mundo todo. Essas diferenças estão relacionadas principalmente ao desenvolvimento econômico, à dieta, ao tabagismo, ao álcool, às viroses e a exposições ambientais e ocupacionais, que de alguma forma, estão ligados também às desigualdades sociais (Otero, Antoniazzi et al., 2007).

Os principais fatores de riscos relacionados ao câncer de laringe são o consumo de álcool e o hábito tabagista (Dosemeci, Gokmen et al., 1997) e sua incidência apresenta-se diminuída nos indivíduos com baixo consumo de álcool e fumo (Tuyns, Esteve et al., 1988). Adicionalmente, o consumo associado de álcool e cigarro pode multiplicar os riscos para desenvolver a doença (Tuyns, Esteve et al., 1988; Zatonski, Becher et al., 1991). O cigarro contém uma mistura de pelo menos 50 componentes, 
incluindo carcinógenos como hidrocarbonetos aromáticos policíclicos, nitrosaminas, aldeídos, e aminas aromáticas (Scully, Field et al., 2000). Muitos desses componentes formam aductos com o DNA, sendo que em fumantes apresentam uma maior quantidade de aductos e de quebras no DNA das células em tecidos de laringe do que não-fumantes (Szyfter, Hemminki et al., 1996; Phillips, 2002). As bebidas alcoólicas também contêm carcinógenos e pró-carcinógenos, incluindo o etanol e as nitrosaminas. O acetaldeído, um dos produtos do metabolismo do etanol, é citotóxico e resulta na produção de radicais livres e bases hidroxiladas no DNA (Scully, Field et al., 2000).

Há evidências de carcinogenicidade, não só de laringe mais de outros órgãos, surgirem devido à exposição ocupacional a agentes tóxicos, tais como o gás mostarda, corantes capilares, níquel, pó de madeira, produtos de borracha, fumaça de diesel/gasolina, formaldeído, amianto, solventes orgânicos, óleo mineral e carvão em pó (Shangina, Brennan et al., 2006). Ainda, outros fatores de risco associados ao câncer de laringe são deficiência de micronutrientes, refluxo, e além desses, vários estudos apontam a infecção elo Papilomavírus Humano (HPV) no desenvolvimento desse tipo de câncer (El-Serag, Hepworth et al., 2001; Xavier, Bussoloti Filho et al., 2005; Ragin, Modugno et al., 2007; Garavello, Giordano et al., 2008).

\subsection{O PAPILOMAVÍRUS HUMANO (HPV)}

Pertencente a família Pavoraídae e envolvido por um capsídio composto de duas proteínas estruturais, o HPV é um pequeno vírus que possui um genoma circular em dupla fita de DNA. Seu genoma contém duas regiões principais, constituídas por genes 
denominados E (early) e L (late), estes genes são responsáveis pela codificação de proteínas viral (Zur Hausen, 2002).

A região E (early) é constituída por oito genes-E1 a E8, sendo responsável pela codificação de proteínas envolvidas na replicação viral e pelo processo de imortalização celular nos HPVs de alto risco. Essa região interfere também nos processos de controle do ciclo celular, resposta apoptótica, sinalização celular e expressão gênica. A proteína E1 possui atividade de helicase e ATPase, além de interagir com outra proteínas. (Wilson, West et al., 2002).

Um conjunto de proteínas que juntas determinam a regulação positiva ou negativa da transcrição dos genes virais, foram mapeadas em regulatórias virais (produtos da E2) ou celulares como fatores de transcrição da célula hospedeira (Scheffner, Romanczuk et al., 1994; Zur Hausen, 2002).

As proteínas E6 e E7 são capazes de imortalizar células humanas e também de desativar supressores tumorais, favorecendo a atividade proliferativa celular e, assim, colaborando para a transformação maligna. (Tommasino, Accardi et al., 2003).

Sabe-se que as oncoproteinas E6 e E7 de HPVs de alto risco se ligam a algumas proteínas de controle do ciclo celular, exercendo uma função de degradação e inativação das mesmas. Dependendo do potencial oncogênico do HPV a afinidade dessas oncoproteinas E6 e E7 por produtos de genes supressores é diferente.

A região L (late) codifica as proteínas estruturais necessárias para a formação do capsídio viral (Heise, 2003). As regiões L1 e L2 possuem seqüência gênica conservada entre todos os tipos de HPV sendo responsáveis pela codificação de proteínas 
constituintes do capsídio viral, as quais respondem por sua antigenicidade. (Munger e Howley, 2002).

Entre os genes L1 e o início da região E6 está a região não codificadora, a região chamada long control region (LCR) ou upstream regulatory region (URR), sendo uma região representa $15 \%$ do genoma viral e contém genes responsáveis pelo controle da replicação do HPV (Sousa, Dostatni et al., 1990; Cheah e Looi, 1998).

Sabe-se que a transcrição na célula infectada ocorre de maneira diferenciada dependendo da interação entre genoma viral com o da celular da célula hospedeira e também da diferenciação celular. (Zur Hausen, 2002).

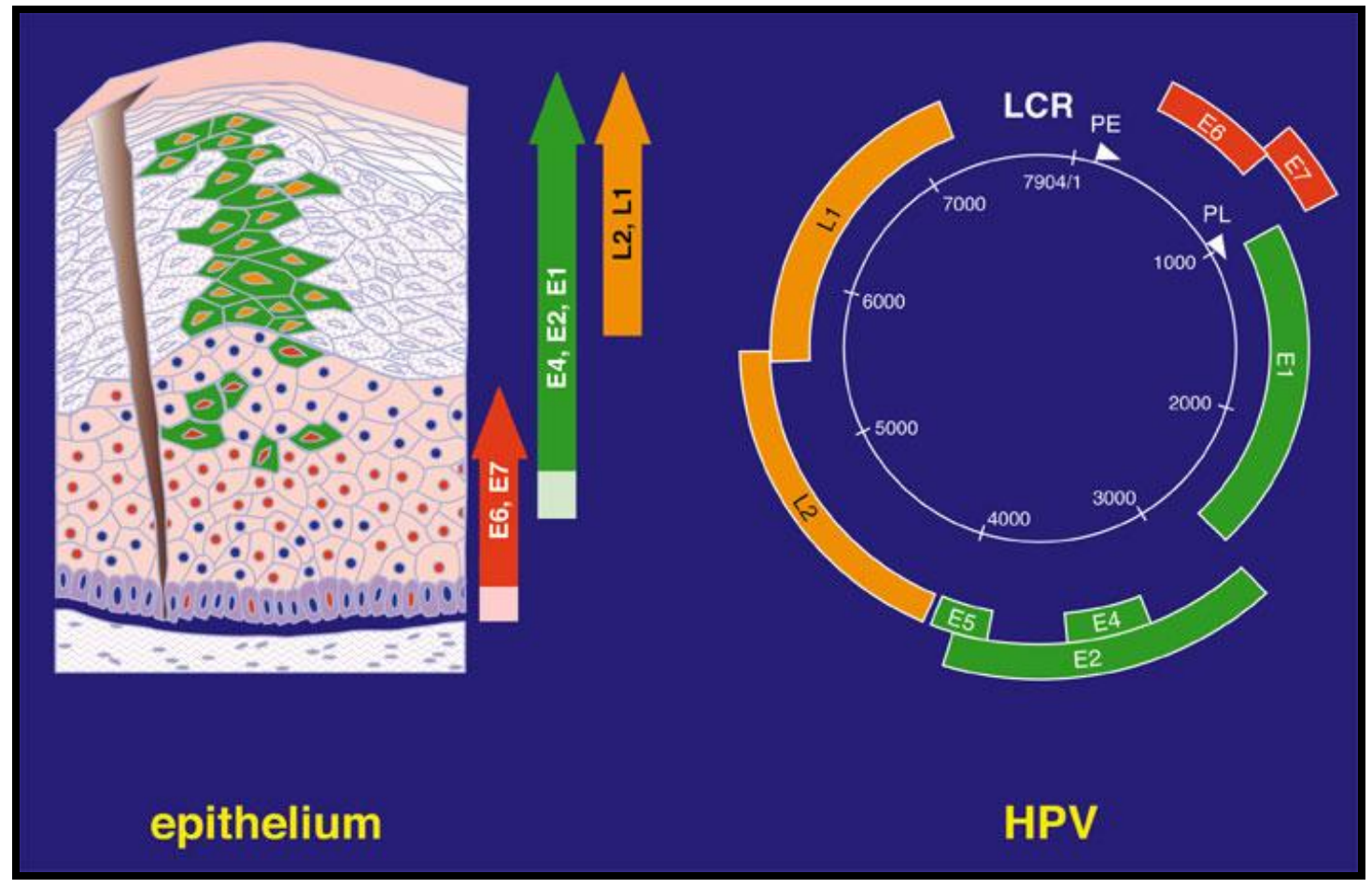

Figura 1 - Extraído da homepage do National Institute for Medical Research. http://www. nimr. mrc. ac.uk/virology/doorbar/lifecycle/fig1/ 
A Figura 1 mostra o ciclo de vida do HPV em relação à diferenciação celular. Em vermelho estão demonstrados os genes de E6 e E7 expressos na camada basal e para basal, relacionados com a manutenção e proliferação do vírus. Em verde está demonstrada a relação de expressão dos genes E4, E1 e E2, que participam da amplificação do genoma viral nas camadas intermediárias do epitélio infectado. Em azul está demonstrado o DNA viral no interior do núcleo das células basais e intermediárias. Em laranja, a expressão dos genes tardios relacionados com o empacotamento do DNA viral na camada superficial. Nas células da camada superficial queratinizadas os vírus são liberados (Zheng e Baker, 2006).

\subsection{TIPOS DE HPV E TROPISMO CELULAR}

Atualmente já foram completamente descritos 118 tipos de HPV e um grande número de presumidos novos tipos virais (De Villiers, Fauquet et al., 2004). De acordo com as propriedades biológicas, os tipos de HPVs são divididos em dois grupos: cutâneotrófico e mucosatrófico. No grupo cutâneotrófico, encontra-se o HPV 1, agente etiológico da verruga plantar, os HPVs 2 e 4 que causam as verrugas comuns e cerca de vinte ou mais tipos virais associados à epidermodisplasia verruciforme (De Villiers, 1997). Por outro lado, no grupo mucosatrófico encontram-se os tipos de HPV 6, 11, 16, $18,31,33,45$, entre outros.

Em relação à contaminação da região de orofaringe, as formas de contaminação e transmissão do vírus são algumas vezes especulativas. A infecção na laringe, faringe e 
esôfago pode ocorrer principalmente no parto, quando o recém-nascido, ao atravessar o canal vaginal, entra em contato com o fluido local contaminado. Sendo assom a contaminação puerperal é uma das explicações para a presença viral na cavidade oral, laríngea e no esôfago. Além disso, a transmissão orogenital é outra hipótese plausível e que explicaria a presença dos tipos anogenitais de HPV na orofaringe (Zur Hausen, 1996).

\subsection{ONCOGÊNESE DO HPV}

Os tipos de HPV de pele ou mucosa podem ser classificados como de baixo ou de alto risco de progressão para câncer, na dependência da interação do DNA viral com o genoma da célula hospedeira (Bonfiglio, 1997). No processo de integração, especialmente dos vírus de alto risco, o sítio de inserção do DNA viral é bastante constante e ocorre entre os genes E1/E2 do HPV, ocasionando a ruptura do gene E2. Normalmente a região E2 reprime a transcrição dos genes virais E6 e E7 e a ruptura de E2, favorece a estabilidade do mRNA de E6/E7, resultando no aumento da expressão desses genes e, conseqüentemente, no aumento dos níveis de seus produtos, podendo assim interagir com proteínas reguladoras do ciclo celular (Vousden, 1993).

O envolvimento do HPV com a carcinogênese celular tem sido alvo de diversos estudos com o objetivo de melhor compreender os fatores virais e celulares responsáveis pelos eventos de transformação maligna (Syrjanen e Syrjanen, 1999; Mcglennen, 2000; Zur Hausen, 2002). Estudos com HPVs de alto risco oncogênicos permitiram definir a importância do modo de replicação (integrado ou epissomal) e a função dos genes 
precoces E6 e E7 nos eventos de proliferação celular (Munger e Howley, 2002). Os produtos dos genes de E6 e E7 dos HPVs de alto risco codificam proteínas multifuncionais que interferem no crescimento celular, estando diretamente envolvidos nos eventos de transformação celular (Tommasino, Accardi et al., 2003). Na infecção por HPV, existem evidências que as oncoproteinas E6 e E7 de HPVs de alto risco se ligam a algumas proteínas de controle do ciclo celular, promovendo degradação e conseqüente inativação de função dessas. A afinidade das oncoproteinas de HPV pelos produtos dos genes supressores tumorais é diferente, a depender do potencial oncogênico do HPV. As proteínas E6 e E7 derivadas de HPV de alto risco (tipos 16,18 e 31) ligam-se a pRb e a p53 com alta afinidade, enquanto que os produtos gênicos E6 e E7 dos papilomas vírus humanos de baixo risco (tipo 6 e 11) ligam-se com baixa afinidade. Portanto, a ação das proteínas E6 e E7 do HPV de alto risco tornam essas duas importantes proteínas supressoras de tumor incapazes de regular ciclo celular (Zur Hausen, 1996).

A proteína E7 tem a capacidade de ligar-se à forma hipofosforilada da proteína supressora tumoral pRb, promovendo sua degradação (Dyson, Buchkovich et al., 1989). Na ausência de pRB, o fator de transcrição E2F permanece constantemente livre, resultando no estímulo de progressão de ciclo celular da fase G1/S sem o reparo de eventuais danos genômicos.

Por Sua vez, a ligação da proteína de E6 de HPVs de alto risco resulta na degradação da p53, uma proteína supressora de tumor que determina a parada do ciclo celular para o reparo de danos no DNA genômico. Dessa forma, o complexo gerado por E6/p53 remove o controle p53-dependente do ciclo celular, provocando o aumento de 
divisão celular, com instabilidade cromossômica e acúmulo de várias mutações na célula infectada (Scheffner, Romanczuk et al., 1994; Zur Hausen, 1996). No entanto, a ligação da proteína de E6 de HPVs de baixo risco à p53 não resulta em sua degradação e, portanto não colabora para os eventos de carcinogênese (Li e Coffino, 1996). Ainda, a oncoproteína E6 poderia degradar a proteína pró-apoptótica BAK, prevenindo a apoptose celular e aumentando da instabilidade cromossômica (Jackson, Harwood et al., 2000).

\subsection{HPV E O CÂNCER DE LARINGE}

Em relação aos carcinomas do trato respiratório superior, o HPV foi considerado como um fator de alto risco. (Pintos, Franco et al., 1999). A associação do HPV com o câncer de laringe foi pela primeira vez sugerida quando foram detectados efeitos citopáticos típicos de HPV nessas lesões (Syrjanen e Surjanen, 1981). A evidência mais convincente da associação entre o HPV e o câncer de laringe foi verificada nos estudos que observaram o DNA do HPV no carcinoma de laringe. (Syrjanen e Syrjanen, 1987; Syrjanen e Puranen, 2000; Herrero, Castellsague et al., 2003). Tipos de HPV similares aos encontrados no colo uterino foram também observados no câncer de laringe, língua e orofaringe. (De Villiers, 1997; Gorgoulis, Zacharatos et al., 1999). Ainda, têm-se evidenciado em estudos recentes que a infecção pelo HPV aumenta significativamente o risco para cânceres de orofaringe (Gillison e Shah, 2001; Mork, Lie et al., 2001). A frequiência de infecção pelo HPV pode variar entre 3\% a $85 \%$ em função do método de detecção empregado e em estudos que utilizam método de menor sensibilidade, como a 
hibridização in situ, a associação entre HPV e câncer de laringe foi encontrada em apenas 5 a 11\% (Scheurlen, Stremlau et al., 1986; Syrjanen e Syrjanen, 1987; Atula, Grenman et al., 1999; Venuti, Manni et al., 2000; Jacob, Sreevidya et al., 2002).

Entretanto, alguns estudos demonstram uma freqüência muito baixa de infecção pelo HPV em carcinoma de laringe, sugerindo que possivelmente a infecção viral possa não ser a principal causa para a malignização desse epitélio (Lindeberg e Krogdahl, 1997; Syrjanen, 2005).

\section{6. bcl-2}

Os eventos de morte celular são classificados em necrose e apoptose e podem ser diferenciados pela morfologia e vias bioquímicas celulares. A necrose é uma forma metabolicamente passiva de morte e ocorre quando a célula não pode manter a homeostasia. Ocorre então liberação de componentes intracelulares e resposta inflamatória, que promove intumescimento celular, digestão aleatória do DNA, cariólise, perda da integridade da membrana, e por fim lise celular (Pulkki, 2000). Em contrapartida, a apoptose é uma forma energeticamente ativa e caracterizada por alterações no citoesqueleto, induzindo contração celular sem perda de integridade da membrana e sem resposta inflamatória (Lavin e Mckeown, 1993)

A apoptose é ativada por vias normais ou por vários estímulos, sua ativação por substâncias químicas pode ocorrer por via extrínseca ou intrínseca, as quais convergem sinais pró-apoptóticos para uma única via central com a ativação de caspases sinalizadoras que, por ação proteolítica, atuam sobre caspases efetoras, clivando 
proteínas celulares vitais e levando a morte celular (Alberts e May, 2002). A via intrínseca é a mais comum, sendo ativada pela própria célula como uma resposta ao estresse gerado por algum dano e envolve a liberação do citocromo c, que é um cofator essencial para ativação das caspases e é regulada pela família das proteínas bcl-2 que ativa a cascata de caspases (SÁNCHES-ALONSO et al, 2004). Bcl-2 é uma proteína de $26 \mathrm{KDa}$, produto de um proto-oncogene localizado no cromossomo 18, que faz parte da família de proteínas bcl-2, a qual possui cerca de vinte membros identificados até o momento e cada uma delas apresentam duas ou mais isoformas. Todas essas proteínas estão associadas à face interna da membrana plasmática, retículo endoplasmático e mitocôndrias (Hockenbery, Nunez et al., 1990). O mecanismo de apoptose é regulado pela expressão de proteínas com funções antagônicas, denominadas pró-apoptótica e anti-apoptótica. As proteínas bax, bak, bcl-Xs, bad, bid tem função pró-apoptótica, enquanto as proteínas bcl-2, bcl-X, Bcl-w, Mcl-1, PARP-1 (poli-ADP-ribose polymerase) tem função anti-apoptótica (Korsmeyer, 1999).

O aumento da expressão de bcl-2 é encontrado em vários tipos de câncer, tais como o câncer de mama, de ovário, cervical e linfoma (Crawford, Caldwell et al., 1998; Dimitrakakis, Kymionis et al., 2000). A expressão anormal da proteína bcl-2 também tem sido amplamente demonstrada em uma variedade de tumores, incluindo malignidades hematológicas (Hanada, Delia et al., 1993), carcinoma de próstata (Colombel, Symmans et al., 1993) e carcinoma de pequenas células do pulmão (BenEzra, (Kornstein et al., 1994). Entretanto, essa proteína também pode apresentar altos níveis nas hiperplasias simples, mas diminui na hiperplasia atípica e no adenocarcinoma endometrial (Ioffe, Papadimitriou et al., 1998). 
Outros estudos verificaram ausência da expressão de bcl-2 nas lesões orais que evoluíram para câncer (Chang, Su et al., 2002) e baixos níveis dessa proteína no carcinoma cervical microinvasor (Kohlberger, Edwards et al., 2003).

Gillet e Brum (1996) observaram um aumento de expressão de bcl-2 nos linfomas foliculares humanos, atuando como uma oncoproteína que contribui para a transformação maligna, portanto, agindo como um inibidor da apoptose.

Desde 1992, Hockenbery (1992) afirma que em grandes quantidades, primariamente induzida por vários estímulos, incluindo aqueles associados aos danos no DNA celular, a proteína bcl-2 impede que as células sejam encaminhadas para a apoptose.

De acordo com Kerr et al (1994) aparentemente, a ação de p53 e bcl-2 são recíprocas, ou seja, o aumento da expressão de p53 resulta em níveis aumentados da proteína bcl-2. Para os mesmos autores, em condições normais o gene P53 codifica a proteína tipo selvagem, ou seja, não mutada, impedindo que as células com alteração genômica prossigam no ciclo celular, o qual fica interrompido na fase G1 até o reparo do DNA. Ainda em 1994, El- Deiry et al (1994) verificaram que o produto do gene p53 controla o gene bcl-2, encaminhando a célula para a apoptose em resposta aos danos no DNA genômico (Figura 2). 


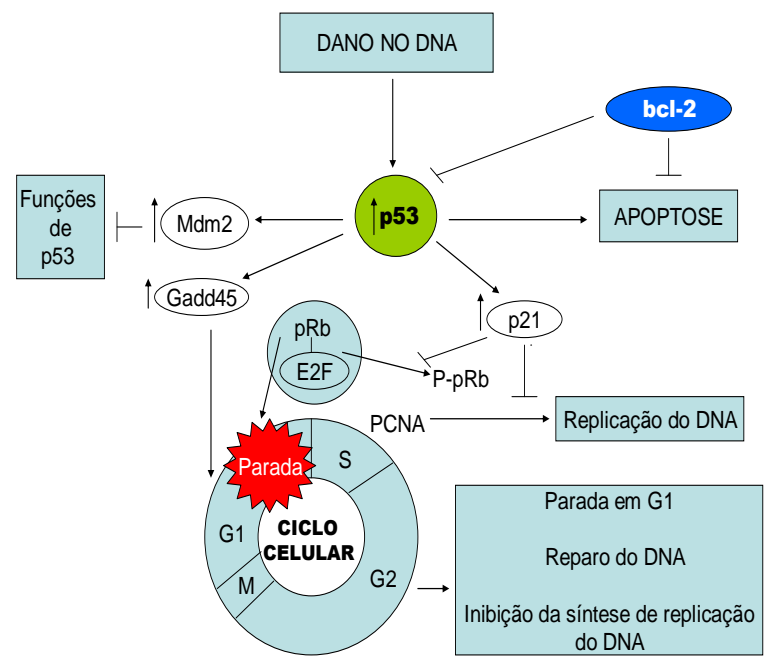

Figura 2. Mecanismo proposto para a ação de p53 em resposta ao dano no DNA e sua interação com a proteína bcl-2 (Kurvinen, Syrjanen et al., 1996).

O aumento da expressão de bcl-2 está relacionado à degradação da proteína p53, ocasionada pela ação das oncoproteinas virais, especialmente E6 dos tipos de HPV de alto risco (Grace, Shalini et al., 2003). Quando a oncoproteinas E6 do HPV se liga a proteína p53 promove a sua degradação mediada pela ubiquitina. Assim, por mecanismo diferente daqueles observados nos tumores, a infecção viral prejudica o mecanismo de reparo em G1, não reprime a expressão de bcl-2, que por sua vez, em quantidade aumentada, ocasiona maior sobrevida da célula transformada (Hockenbery, Nunez et al., 1990; Kerr, Winterford et al., 1994; Syrjanen e Syrjanen, 1999). Experimentos in vitro, utilizando células CaSki infectadas por HPV16, verificaram que a inativação e/ou um baixo nível de p53 estão associados com o aumento da expressão de bcl-2, o que pode contribuir para a transformação maligna (Miyashita, Krajewski et al., 1994; Liang, Mungal et al., 1995). A distribuição da intensidade de expressão de bcl-2 maior nas 
lesões de alto grau infectadas com os tipos de HPV16 e 18, quando comparadas a menor expressão de bcl-2 em lesões de baixo grau infectadas com tipos virais de baixo risco, demonstram que bcl-2 também poderia ser utilizado como marcador de malignidade associada à infecção pelo HPV (Syrjanen e Syrjanen, 1999).

\subsection{PARP-1}

PARP é uma família de enzimas presentes nas células eucarióticas responsáveis pela poli-ADP-ribosilação, constituída de várias isoenzimas dentre elas as denominadas PARP-1, PARP-2 e PARP-3 (Lautier, Lagueux et al., 1993; Nguewa, Fuertes et al., 2003). A poli-ADP-ribosilação é essencial para manter a integridade do genoma, na qual polímeros de poli ADP ribose são sintetizadas por uma família de enzimas polimerases (PARP), utilizando nicotinamida acetil dinucleotídeo $\left(\mathrm{NAD}^{+}\right)$como substrato $(\mathrm{KOH}$ et al, 2005). Essas enzimas têm surgido como um componente da regulação na resposta a danos no DNA, em particular pela sua função no reparo de DNA por excisão de base (Schreiber, Hunting et al., 1995; Ruf, Mennissier De Murcia et al., 1996). PARP-1 é uma enzima nuclear e consiste de três domínios A-F (Figura 3) (Drew e Calvert, 2008). O processo de poli-ADP-ribosilação é iniciado principalmente por PARP-1, colaborando para a regulação da morte celular em células após a mitose (Koh, Dawson et al., 2005.) 


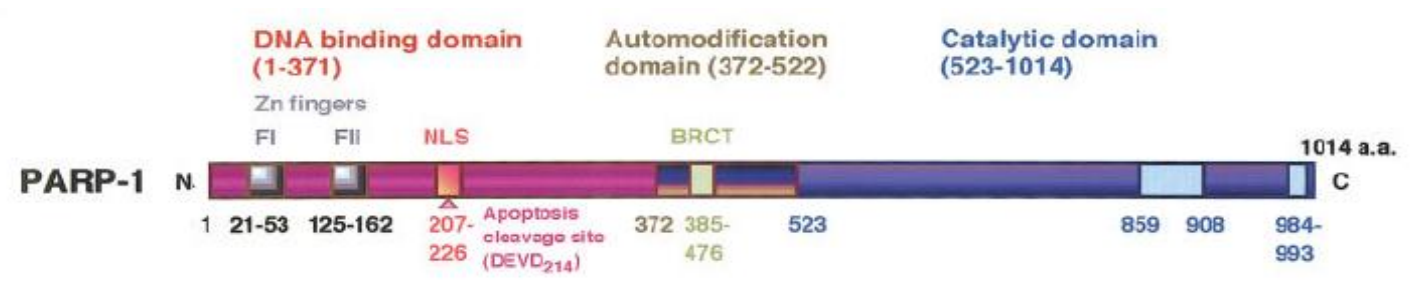

Figura 3 - Representação esquemática dos três domínios PARP-1 humano (Chang, Jacobson et al., 2004).

A proteína PARP-1 é considerada importante para sinalização constitutiva de sinais de reparo e para a maquinaria de controle do ciclo celular, podendo colaborar com os sinais de sobrevida celular (Bouchard, Rouleau et al., 2003). PARP-1 parece participar de processos de regulação da transcrição e controle da diferenciação, prevenindo a carcinogenese celular (Yu, Wang et al., 2002; Masutani, Nakagama et al., 2003). Sob condições normais, PARP-1 na forma inativa pode ser observada no nucleoplasma (Smith, 2001), bem como na mitocôndria (Du, Zhang et al., 2003). Estudos prévios têm demonstrado que a PARP-1 é sintetizada após a ativação do mecanismo de apoptose (Rosenthal, Ding et al., 1997) e a degradação de PARP-1 é geralmente considerada como um marco da apoptose (Duriez e Shah, 1997). Recentemente foi proposto que a clivagem de PARP-1 durante a apoptose está associada ao decréscimo de poli-ADP ribosilação de uma endonuclease, permitindo a ocorrência de degradação do DNA (Soldani, Bottone et al., 2001). (Figura 4) 


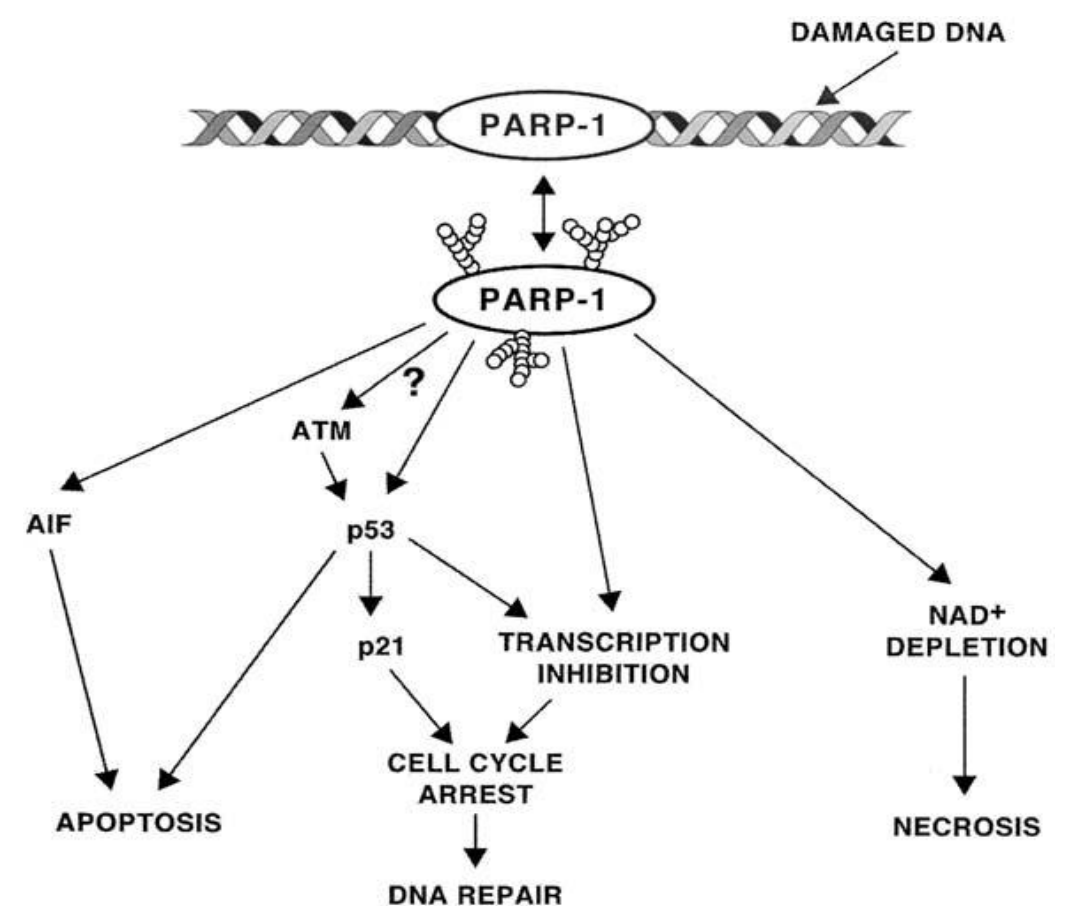

Figura 4 - Modelo de dano no DNA e sinalização de PARP-1 (Bouchard, Rouleau et al., 2003)

Deficiência de PARP-1 pode contribuir na carcinogênese através da indução da instabilidade gênomica, de alterações epigenéticas e alterações na regulação e diferenciação transcripcional. Aumento de PARP-1 tem sido descrito em vários outros tipos de cânceres como: sarcoma de Ewing's e linfomas malignos (Masutani, Nakagama et al., 2005), carcinoma hepatocelular (Shimizu, Nomura et al., 2004) e carcinoma endometrial (Ghabreau, Roux et al., 2004)). Já o decréscimo dessa proteína tem sido observado em câncer gástrico, cólon ((Masutani, Nakagama et al., 2005) e câncer de mama (Bieche, De Murcia et al., 1996).

Staibano et al (2005) sugerem que a progressão neoplásica e invasão através da fase de crescimento dos melanócitos em melanomas malignos é caracterizada pela perda 
de clivagem de PARP-1, provavelmente sinalizando a instabilidade do processo apoptótico nessas células predispondo a alterações malignas.

Recentes estudos demonstram que PARP-1 está associada à regulação da proteína p53 tipo selvagem e poderia também apresentar alguma desregulação, sabendose que a oncoproteína E6 dos tipos de HPV de alto risco promovem a degradação de p53 (Wsierska-Gadek e Horky, 2003). De fato, é muito possível a interação de tipos de HPV de alto risco e PARP-1, visto que estudos experimentais demonstram que PARP-1 tem função de co-ativadora de proteína E2 de HPV18 e sua alta expressão estaria relacionada com estímulo de transcrição de E2 (Lee, Kim et al., 2002). Entretanto, até o momento e segundo nosso conhecimento, nenhum trabalho relacionou o papel de PARP-1 no descontrole dos sinais de apoptose em câncer de laringe associado à infecção pelo HPV.

\subsection{GALECTINA - 3}

Dentre as proteínas da família das galectinas, a galectina-3 está envolvida em múltiplos processos biológicos, que incluim o tanto o crescimento celular e apoptose. A galectina-3 é proteína monomérica (Figura 5) com alta afinidade por betagalactosidases, mediando processos de adesão celular a MEC (Matrix Extarcelular) através do reconhecimento e ligação de seus diferentes domínios a glico-conjugados (Wang, Gray et al., 2004). É considerada uma proteína indutora de mitose (Inohara, Akahani et al., 1998), e de participação no processo de apoptose (Ochieng, Green et al., 1998; Matarrese, Tinari et al., 2000). Várias galectinas, como galectina-1, -2, -7 e -9 têm atuações pró-apopticas, enquanto que a galectina-3 parece agir de uma 
maneira antiapoptótica nos casos de células de vários tipos de tumores (Soasses, Camby et al., 2007).
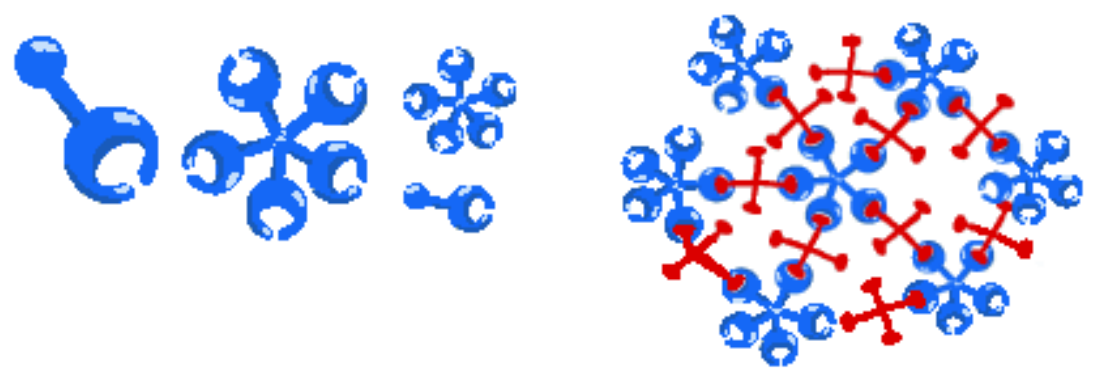

Figura 5 - Representação esquemática de galectina-3 (Saussez, Camby et al., 2007)

A galectina-3 pode ser localizada no núcleo e citoplasma de vários tipos de células dos mamíferos, sendo encontrada em células epiteliais e cartilagem, assim como em células inflamatórias e macrófagos (Liu, Patterson et al., 2002). Todo o papel biológico da Galectina-3 é definido por sua localização celular. Galectina-3 quando localizada no núcleo das células possui um efeito antitumor, apesar de que essa localização nuclear correlaciona-se com uma progressão neoplásica. Entretanto na transformação maligna de células de tireóide observa-se uma intensa marcação nuclear dessa proteína (Dumic, Dabelic et al., 2006).

Entretanto, a distribuição nuclear versus citoplasmática pode ser alterada por inúmeras condições, como tipo de célula, status de proliferação celular, transformação e progressão neoplásica (Dumic, Dabelic et al., 2006). Em cultura de fibroblastos, o 
predomínio de galectina-3 está no núcleo e somente baixa concentração dessa proteína é observada no citoplasma. (Wang, Gray et al., 2004).

A galectina-3 parece estar envolvida em vários processos patológicos incluindo o câncer e doenças infecciosas. E devido a sua função nas interações célula-célula e matriz-célula, tem sido proposta como um marcador de metástase. (Matarrese, Tinari et al., 2000). O aumento de expressão de galectina-3, em diferente localização tecidual e intracelular, parece estar relacionado com a progressão das neoplasias malignas oral, de próstata e carcinoma folicular e papilar da tireóide. (Bartolazzi, Gasbarri et al., 2001; Wang, Gray et al., 2004). Em estudos prévios, nos tumores colos retais, de tireóide, gástricos, de ovário e de mama, o aumento da expressão de a galectina-3 foi observado nos tumores invasivos e metastáticos (Shimonishi, Miyazaki et al., 2001). Apesar de estudos prévios terem demonstrado uma redução da expressão de galectina-3 em carcinoma de paratireóide, altos níveis de galectina foram vistos em tumores primários e metastáticos (Bergero, De Pompa et al., 2005).

Recentemente, foi demonstrado que alterações epigenéticas de galectina no DNA por diferenças de expressão dessa proteína em diferentes tipos de cânceres (Ahmed, Banerjee et al., 2007). Por isso, galectina-3 vem sendo considerada como um importante fator de prognóstico em diferentes tipos de tumores, como câncer coloretal, câncer de cabeça e pescoço, câncer pancreático e câncer gástrico (Puglisi, Minisini et al., 2004).

A Galectina-3 tem sido proposta como um marcador biológico de agressividade em vários tipos de tumores de cabeça e pescoço (Saussez, Camby et al., 2007). No entanto a expressão dessa proteína em tumores de cabeça e pescoço ainda é controvérsia, 
e apesar disso, em consideração as propriedades funcionais da galectina-3 é mais que claro que essa lectina tem um papel importante na patogênese, proliferação e metástase do câncer (Dumic, Dabelic et al., 2006). 
2. OBJETIVOS 


\subsection{OBJETIVO GERAL}

Este estudo tem como objetivo avaliar expressão das proteínas bcl-2 galectina-3 e PARP-1 e o envolvimento do HPV na carcinogênese de laringe bem como sua progressão tumoral nas lesões malignas.

\subsection{OBJETIVOS ESPECÍFICOS}

2.2.1 Verificar a presença do HPV nas lesões malignas de laringe através da detecção e identificação dos tipos de HPV de baixo (6 e 11) ou alto risco oncogênco (16, 18,31 e 33), utilizando o método da reação em cadeia da polimerase (PCR) em lesões fixadas e incluídas em parafina.

2.2.2 Avaliar o envolvimento do HPV na eventual alteração da expressão das proteínas bcl-2 e galectina-3 e PARP-1, e eventual evasão da apoptose, utilizando o método de imunoistoquímica.

2.2.3 Verificar se a avaliação da expressão imunoistoquímica dessas proteínas poderiam ser consideradas bons marcadores para avaliação de progressão tumoral (invasão e metástase). 


\subsection{ASPECTOS ÉTICOS}

O presente estudo foi analisado pelo Comitê de Ética em Pesquisa de Experimentação Humana da Faculdade de Medicina de Ribeirão Preto da Universidade de São Paulo (USP), e enquadrado como APROVADO, de acordo com o Processo ${ }^{\circ}$ 5508/2006 (Anexo 1).

\subsection{AMOSTRAS}

Foram selecionadas 65 biópsias com diagnóstico de carcinoma de laringe, sendo divididas em três subgrupos: 10 carcinomas in situ, 27 carcinoma invasivo sem metástase e 28 carcinoma invasivo com metástase. Nos pacientes com metástase, foram avaliados cortes da lesão primária e de metástases nos respectivos linfonodos. Os blocos de parafina foram selecionados retrospectivamente (1995 - 2004) do arquivo de Serviço de Patologia (SERPAT) do HCFMRP-USP. Em seguida, cortes histológicos corados em hematoxilina-eosina, pertencentes ao arquivo de lâminas do serviço citado, foram reavaliados por patologista experiente.

\subsection{DADOS EPIDEMIOLÓGICOS}

Informações relevantes tais como: idade, sexo, história de tabagismo e consumo de álcool foram coletadas dos laudos obtidos do serviço de prontuários, SAME (Serviço de Arquivo Médico) do Hospital das Clínicas de Ribeirão Preto (USP). 


\subsection{PREPARO DAS AMOSTRAS}

As biópsias foram submetidas a novos cortes histológicos de $5 \mu \mathrm{m}$ de espessura, os quais foram colocados em laminas pré-tratadas com organosilano e submetidos ao método de imunoistoquímica para a avaliação das proteínas bcl2, PARP1 e Galectina-3. Adicionalmente, outros cortes histológicos das mesmas biópsias, com espessura de $10 \mu \mathrm{m}$, foram utilizados para os procedimentos de extração de DNA, detecção e identificação dos tipos de HPV 6, 11, 16, 18, 31 e 33.

\subsection{REAÇÃO DE IMUNOISTOQUÍMICA}

3.5.1 Reação de imunoistoquímica (bcl-2, galectina-3 e PARP-1)

Para detecção das proteínas bcl-2, Galectina-3 e PARPl as reações de imunoistoquímica foram realizadas utilizando o método de imunoperoxidase (Novostain, Novocastra, Newcastle, UK). Os cortes foram desidratados em xilol, reidratados em graduação alcoólica crescente e enxaguados em água. Para recuperação antigênica, as lâminas foram imersas em citrato de sódio tamponado , $\mathrm{pH}$ 6,0, e fervidos em panela a vapor na temperatura de $95^{\circ}$ a $99^{\circ}$ por 40 minutos. Para inibir a peroxidase endógena, os cortes foram tratados com peróxido de hidrogênio a 3\% por 20 minutos. A seguir, os cortes foram lavados três vezes com PBS e incubados com soro normal de

cavalo por 30 minutos. Posteriormente os cortes foram incubados com anticorpo 
primário contra bc12 (diluído 1:100, DAKO Gostrup, Denmark), Galectina-3 (diluído 1:100, Freemont, CA, USA) e PARP-1(diluído 1:100, Santa Cruz) em câmara úmida temperatura ambiente overnight. Após a incubação com o anticorpo primário, as lâminas foram lavadas três vezes em PBS, incubadas, consecutivamente, com anticorpo secundário biotinilado (LSAB, DAKO, Glostrup, Dinamarca) e complexo estreptavidina-biotina-peroxidase ( $\mathrm{LSAB}, \mathrm{DAKO})$, a $37^{\circ} \mathrm{C}$ por 30 minutos a cada incubação. Entre cada um dos procedimentos acima descritos, as lâminas foram cuidadosamente lavadas três vezes em solução de PBS. Subseqüientemente as lâminas foram incubadas com $100 \mu \mathrm{l}$ da solução contendo 5mg de diaminobenzidina (DAB, GIBBICO, Gaithersburg, Maryland, USA), dissolvida em 5ml de PBS e em $120 \mu 1$ de peróxido de hidrogênio. A reação foi bloqueada com uma lavagem em PBS, seguida por lavagem com água destilada. Depois as lâminas foram levemente contra coradas com hematoxilina de Harris por 60 segundos para bcl2, galectina3 e PARPl e lavados em água corrente. A seguir foram reidratadas em três soluções de álcool absoluto, seguidas de duas imersões em xilol e montadas com Permount (MERCK, Darmstadt, Alemanha).

\subsubsection{Controles}

Dois controles foram incluídos para cada reação e para todas as proteínas avaliadas: positivo e negativo. Os controles positivos foram cortes histológicos de carcinoma de laringe (bcl-2), Linfoma não Hodking (Galectina-3 e PARP-1). Os controles negativos foram os mesmos tecidos humanos, apenas omitindo-se a etapa de incubação com anticorpo primário. 


\subsection{ANÁLISE QUALITATIVA DE bcl-2, Galectina- 3 e PARP-1}

Após a reação de imunoistoquímica a imunomarcação as proteínas bcl-2, Galectina-3 e PARP-1 foram avaliadas por um único patologista e classificada como marcação negativa, leve, moderada e intensa, de acordo com a intensidade de marcação e distribuição da imunomarcação no corte histológico. Foi considerada a expressão de bcl-2, Galectina-3 e PARP-1 como sendo baixa quando as biópsias de laringe foram negativas ou mostraram discreta imunomarcação. Expressão de bcl-2, Galectina-3 e PARP-1 foi classificada como alta quando o patologista observou moderada ou intensa imunomarcação.

\subsection{AQUISIÇÃo DAS IMAgENS E ANÁLISE QUANTATIVA DE bcl-2, Galectina- 3 e PARP-1}

Os citoplasmas (bcl-2, Galectina-3 PARP-1) positivos foram automaticamente quantificados pelo equipamento Image-Pro Plus (Cybernetics, MD, EUA) o qual inclui um microscópio, uma câmera digital e um software para análise de imagem. Em média, oito campos randômicos do microscópio foram selecionados para a análise de 1000 células marcadas (núcleo ou citoplasma) por biópsia em todos os pacientes. A aquisição da imagem das lâminas dos 655 pacientes com carcinoma de laringe (in situ, com e sem metástase) e dos linfonodos cervicais foi realizada por foto micrografia e a imagem 
processada pelo software. Cada lâmina foi digitalizada e a segmentação foi controlada pelo filtro RGB (Red, Green and Blue) existente no programa de análise de imagem. A contagem automática das células positivas foi estabelecida e expressa em porcentagem. As análises quantitativas de bcl-2, Galectina-3 e PARP-1 foram classificadas como negativas quando os níveis das proteínas apresentavam-se insignificantes $(<10 \%)$ ou positivas com valores acima do cut-off (10\%), como proposto por Yamamoto e colaboradores (2002).

\subsection{DETECÇÃO E TIPAGEM DO HPV}

\subsubsection{Extração de DNA genômico de tecido parafinizado}

Os cortes histológicos de $15 \mu \mathrm{m}$ foram transferidos para eppendorfs estéreis, adicionado $200 \mu \mathrm{L}$ de tampão de digestão (50mM Tris-HCl, pH8,5, 1mM EDTA pH 8,0 e $0,5 \%$ de Tween ) e submetidos a aquecimento sem fervura em microondas, a 500W, a 15 segundos por quatro vezes, por 60 segundos. Em seguida, os tubos foramcentrifugados a $12.000 \mathrm{rpm}$ por 10 minutos a temperatura ambiente. $\mathrm{O}$ sobrenadante foi transferido para outro eppendorf, adicionada solução de proteinase $\mathrm{K}$ $(200 \mu \mathrm{g} / \mathrm{mL})$, incubados em Banho Maria, a $42^{\circ} \mathrm{C}$, overnight, seguida pela inativação da proteinase $\mathrm{K}$ a $96^{\circ} \mathrm{C}$ por 10 minutos. Os tubos foram submetidos aos procedimentos de extração com $\mathrm{NaCl}$ 6M, e centrifugação a $10.000 \mathrm{rpm}$, por 10 minutos. O sobrenadante foi transferido e a ele acrescido $1.000 \mu \mathrm{L}$ de etanol absoluto, homogeneizando e centrifugando por 15 minutos a $10.000 \mathrm{rpm}$. O sobrenadante será retirado, o precipitado 
lavado com etanol $70 \%$ e novamente centrifugado a $10.000 \mathrm{rpm}$, por 5 minutos. O sobrenadante foi desprezado, e seu precipitado seco a $37^{\circ} \mathrm{C}$ foi ressuspendido em tampão TE. A concentração e pureza do DNA serão obtidas após leitura espectofotométrica nos comprimentos de onda de $260 \mathrm{~nm}$ e $280 \mathrm{~nm}$.

\subsubsection{Amplificação com primers consenso GP5+/GP6+}

A reação de polimerização em cadeia foi realizada, utilizando os primers consenso GP5+/GP6+. A amplificação do gene de betaglobina (primers PC04/ GH20) foi utilizada para avaliação da integridade do DNA genômico pós-extração. Para cada amostra de DNA gênomico foram adicionados no eppendorf os seguintes reagentes: $3,5 \mu \mathrm{L}$ de tampão da enzima $10 \mathrm{X}, 1,5 \mu \mathrm{L}$ de $\mathrm{MgCl}_{2} 50 \mathrm{mM}, 0,5 \mu \mathrm{L}$ de dNTP $10 \mathrm{mM}$, $1,0 \mu \mathrm{L}$ do primer GP5+ $10 \mu \mathrm{M}, 1,0 \mu \mathrm{L}$ do primer $\mathrm{GP} 6+10 \mu \mathrm{M}, 0,25 \mu \mathrm{L}$ de Taq DNA polimerase $500 \mathrm{U}$ e $2,0 \mu \mathrm{L}$ de DNA a $100 \mathrm{ng} / \mu \mathrm{L}$. O volume final da reação foi de $25 \mu \mathrm{L}$. Os ciclos da reação foram estabelecidos segundo (HUSMAN et al, 1995) e modificados posteriormente nas etapas de padronização. A reação em cadeia de polimerase para o gene de betaglobina foi utilizada como controle de amplificação e integridade do DNA.

Os ciclos da reação foram estabelecidos segundo (Iwasawa, Nieminen et al., 1997).

3.8.3 Amplificação com primers tipo específico (HPV 6/11, 16, 18, 31 e 33)-biópsias parafinizadas 
A reação de tipificação dos $\operatorname{HPV} 6,11,16,18,31 \mathrm{e} 33$ foi realizada utilizando primers específicos e cada reação foi acompanhada de controle positivo e negativo para HPV, sendo que os controles positivos para HPV 16 e HPV 18 foram gentilmente cedidos pela Dra Luisa Lina Villa, do Instituto Ludwig para a Pesquisa do Câncer. A reação de PCR para a detecção do DNA do HPV 6/11, 16, 18 e 31 viral foi realizada com os seguintes reagentes: $3,5 \mu \mathrm{L}$ de tampão da enzima $10 \mathrm{X}, 1,25 \mu \mathrm{L}$ de $\mathrm{MgCl}_{2} 50 \mathrm{mM}$, $0,5 \mu \mathrm{L}$ de dNTP $10 \mathrm{mM}, 1,0 \mu \mathrm{L}$ de cada primer na concentração de $10 \mu \mathrm{M}$ SL6/11 A e S VdB18 D e U, VdB 31 D e U, 0,25 $\mu \mathrm{L}$ de Taq DNA polimerase $500 \mathrm{U}$ e $2,0 \mu \mathrm{L}$ de DNA a $100 \mathrm{ng} / \mu \mathrm{L}$. O volume final da reação foi de $25 \mu \mathrm{L}$. Os ciclos foram : desnaturação 1 ciclo de $94^{\circ} \mathrm{C}$ por 7 minutos, 35 ciclos de desnaturação $\left(94^{\circ} \mathrm{C}-45\right.$ segundos), hibridização $\left(57^{\circ} \mathrm{C}\right.$ - 30 segundos $)$, extensão a $\left(72^{\circ} \mathrm{C}-1\right.$ minuto $)$ e uma extensão final a $72^{\circ} \mathrm{C}$ por 10 minutos. Para a reação de amplificação com primers tipo específico para HPV 33 (VdB $33 \mathrm{D}$ e $\mathrm{VdB} 33 \mathrm{U}$ ) as mesmas condições de reação e os ciclos da reação serão estabelecidos segundo (HUSMAN et al, 1995)

\subsection{CONTROLES}

Os controles positivos para HPV e beta-globina foram amostras cervicais coletadas pelo método de citologia. Como controle negativo, todos os reagentes de reação de PCR foram adicionados em um tubo de Eppendorf não continha amostras de DNA. Para os tipos de HPV 6 e HPV 11, os controles utilizados foram DNA de Positivo de amostras cervicais. Para controle dos tipos de HPV 16 e HPV 18, foi extraído DNA 
de cultura de células SiHa e HeLa, respectivamente, e por fim para os tipos de HPV 31 e HPV33 foram extraídos DNA de amostras de pacientes positivas para esses tipos de HPV.

\subsection{ANÁLISE ESTATÍSTICA}

Inicialmente foi aplicado o teste de normalidade Kolmogorov-Smirnov para verificar se as amostras seguiam a distribuição normal Gaussiana, no entanto verificouse uma distribuição fora dos padrões normais, portanto os testes não paramétricos foram escolhidos para a avaliação estatística.

A distribuição dos três parâmetros clínicos (idade, e exposição ao fumo e ao álcool), foi comparada entre os diferentes subgrupos de neoplasia maligna de laringe (CLIS, CLS, CLM e LC), pelo Teste Exato de Fisher, também foi usado para a estimativa do odds ratio (OR) com intervalo de confiança de 95\%. A idade, descrita em média aritmética e erro padrão, também foi comparada entre os grupos pelo Teste $\mathrm{T}$ de Student.

Enquanto que, para as análises quantitativas foram aplicados os testes de Wilcoxon, Kruskal-Wallis e Correlação de Spearman. O Teste de Kruskal-Wallis seguido pós-teste de Dunn foi aplicado para comparar a expressão dos níveis de galectina-3, PARP-1 e bcl-2 entre os três subgrupos das neoplasias malignas de laringe (CLIS, CLS, CLM e LC). A média dos níveis de expressão das proteínas (galectina-3, PARP-1 e bcl-2) entre o carcinoma invasivo com metástase (CLM) e Linfonodos 
cervicais (LC) das lesões metastáticas de laringe, foram comparadas pelo Teste de Wilcoxon. Para a análise de correlação entre diferentes proteínas em cada tipo de lesão e entre carcinomas invasivos com metástase e as biópsias de linfonodos cervicais, foi empregado o coeficiente de correlação para postos de Spearman.

$\mathrm{Na}$ análise qualitativa para comparar a distribuição dos diferentes graus de intensidade de marcação (leve, moderada, acentuada e intensa) nos carcinomas com e sem metástases foi utilizado o Teste Exato de Fisher.

As análises estatísticas foram avaliadas pelo software GraphPad Instat 3.05 (GraphPad software, San Diego, CA, USA) e considerados estatisticamente significantes os valores de $\mathrm{p} \leq 0.05$. 
4. RESULTADOS 


\subsection{PARÂMETROS CLÍNICOS E CÂNCER DE LARINGE}

Os parâmetros clínicos dos pacientes com carcinoma de laringe in situ e dos carcinomas invasivos com e sem metástase não demonstraram nenhuma associação significante com relação à idade, sexo ou uso de cigarro (Tabela 1). Entretanto, houve um predomínio de pacientes do sexo masculino quando se tratava ao tabagismo e etilismo.

Tabela 1 - Parâmetros Clínicos dos 65 pacientes com carcinoma de laringe, divididos de acordo com idade, sexo e tabagismo e etilismo.

\begin{tabular}{|c|c|c|c|c|c|c|c|}
\hline \multirow[b]{3}{*}{ CLIS (N=10) } & \multirow{3}{*}{$\begin{array}{c}\text { Idade } \\
\mathrm{M} \pm \mathrm{EP} \\
59.2 \pm 2.56\end{array}$} & \multicolumn{2}{|c|}{ Sexo } & \multicolumn{2}{|c|}{ Tabagismo } & \multicolumn{2}{|c|}{ Etilismo } \\
\hline & & Masculino & Feminino & Sim & Não & Sim & Não \\
\hline & & 6 & 4 & 6 & 4 & 3 & 7 \\
\hline CLS $(\mathbf{N}=27)$ & $59.18 \pm 1.47$ & 18 & 9 & 23 & 3 & 15 & 12 \\
\hline $\operatorname{CLM}(\mathrm{N}=28)$ & $56.07 \pm 1.78$ & 23 & 5 & 28 & 0 & 20 & 8 \\
\hline Comparações & $p$-valor ${ }^{\text {a }}$ & OR & alue $^{b}$ & ( & & & $e^{b}$ \\
\hline CLS vs. CLIS & $\mathrm{p}=0.9945$ & \multicolumn{2}{|c|}{$\mathrm{p}=0.7158$} & \multicolumn{2}{|c|}{$\mathrm{OR}=5.333(0.9321-30.517$} & $\begin{array}{r}\mathrm{OR}= \\
13.760)\end{array}$ & $6.182-$ \\
\hline CLS vs. CLM & $\mathrm{p}=01869$ & $\begin{array}{r}\mathrm{p}=\mathrm{p} \\
\mathrm{OR}=2.300\end{array}$ & $\begin{array}{l}.2270 \\
6553-8.0722)\end{array}$ & $\mathrm{OR}=8.14$ & $65.6501)$ & $\mathrm{OR}=2.0$ & $-6.1153)$ \\
\hline
\end{tabular}

M= Média; E.P =Erro Padrão

CLIS = Carcinoma epidermóide in situ de laringe; CLS = Carcinoma epidermóide invasivo de laringe sem metástase; $\mathbf{C L M}$ = Carcinoma epidermóide invasivo de laringe com metástase em linfonodo cervical. a: Unpaired t test; ${ }^{\text {b. }}$ Fisher's exact test.

$\mathrm{OR}=$ Odds ratio 


\subsection{DETECÇÃO E TIPAGEM DO HPV}

Dos 65 pacientes, $55(84,6 \%)$, foram positivos para beta-globina (controle interno) e 10 pacientes (15.4\%) foram beta-globina negativa, indicando que o DNA estava degradado das biópsias de parafina (Tabela 2). Por isso estes casos foram excluídos da avaliação para detectar DNA de HPV. Por fim, no presente estudo, 7 (12.7\%) dos 55 pacientes foram positivos para HPV, sendo que destes 7 foram, respectivamente, DNA de HPV de baixo risco e alto risco oncogênco 1 (14.3\%), e 6 (85.7\%) .Quarenta e oito (87,3\%) dos 55 pacientes foram HPV negativo (Figura 6).

Tabela 2 - Detecção de DNA de HPV (GP5+/GP6+) e tipagem (primers específicos) em 55 pacientes $(*)$ com carcinoma de laringe dividido de acordo com o diagnóstico histológico.

\begin{tabular}{l|c|c|c|c|c|c}
\hline & $\begin{array}{c}\text { HPV } \\
\text { Positivo } \\
\mathrm{n}(\%)\end{array}$ & $\begin{array}{c}\text { HPV } \\
\text { Negativo } \\
\mathrm{n}(\%)\end{array}$ & HPV6 & HPV18 & HPV31 & $\begin{array}{c}\text { HPV } \\
\text { Dois tipos } \\
\mathrm{n}(\%)\end{array}$ \\
\hline CLIS & $1(14.3)$ & $9(16.4)$ & - & $1(14.3)$ & - & - \\
CLS & $2(28.6)$ & $25(45.5)$ & $1(14.3)$ & - & - & $1(14.3)^{\mathrm{b}}$ \\
CLM & $2(28.6)$ & $26(47.3)$ & - & - & $1(14.3)$ & $2(28.6)^{\mathrm{c}}$ \\
LC & $2(28.6)$ & $26(47.3)$ & - & - & - & $2(28.6)^{\mathrm{c}}$ \\
& & & & & & \\
\hline Total & $7(10.8)$ & $48(87.3)$ & $1(14.3)$ & $1(14.3)$ & $1(14.3)$ & $4(57.1)$ \\
\hline
\end{tabular}

CLIS = Carcinoma epidermóide in situ de laringe; $\mathbf{C L S}$ = Carcinoma epidermóide invasivo de laringe sem metástase; $\mathbf{C L M}$ = Carcinoma epidermóide invasivo de laringe com metástase em linfonodo cervical e $\mathbf{L C}=$ Linfonodos Cervical.

${ }^{\mathrm{a}} \mathrm{HPV} 31$ e $33 ;{ }^{\mathrm{b}} \mathrm{HPV} 6$ e $16 ;{ }^{\mathrm{c}}$ primeiro paciente HPV16 e 31 e segundo paciente HPV16 e33

(*) Em 10 (15.4\%) pacientes, o gene de beta-globina não foi amplificada, indicando degradação de DNA, e esses pacientes não foram considerados nem HPV positivo nem HPV negativo. 

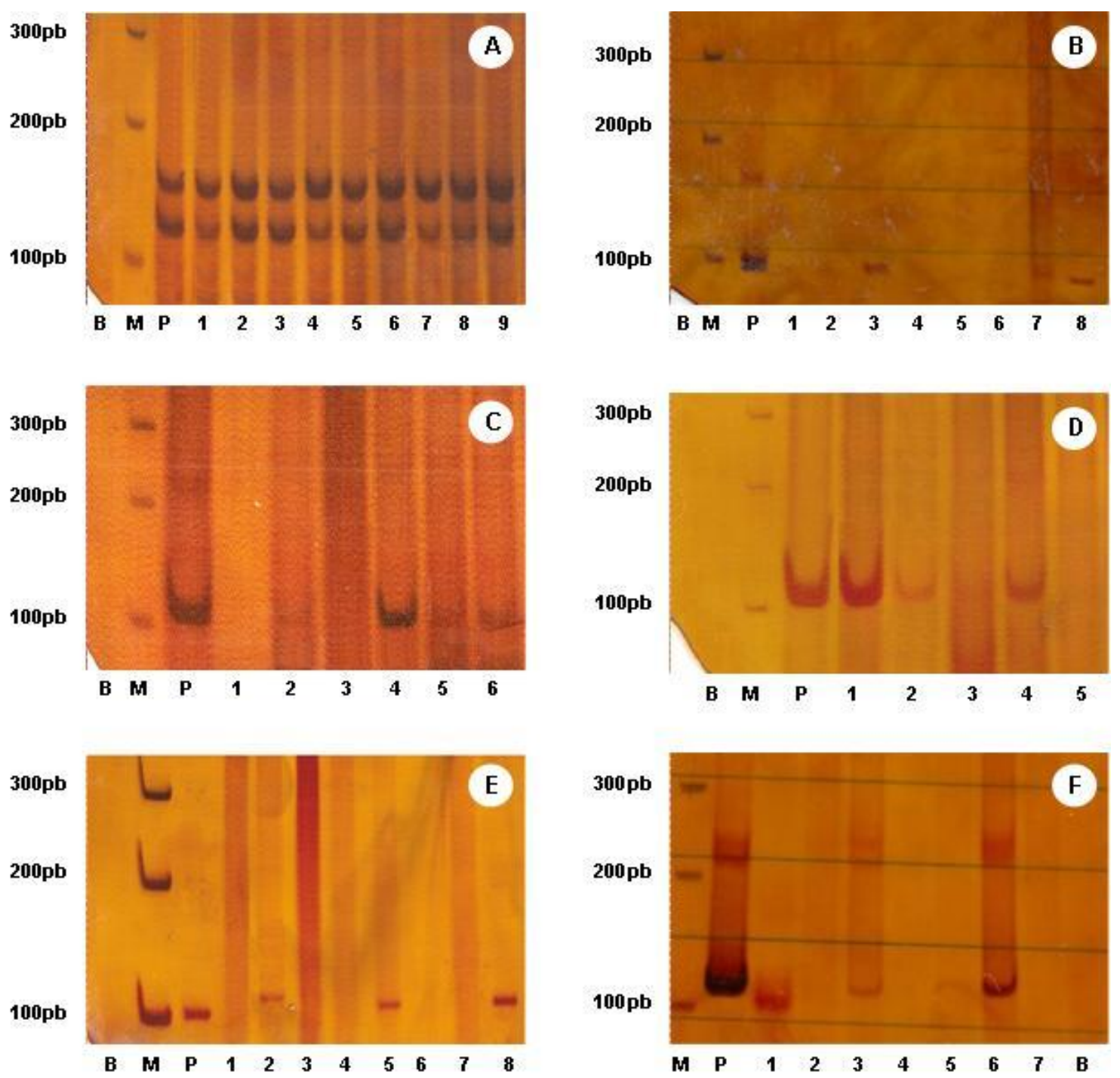

Figura 6 - Reação de polimerização em cadeia da polimerase (PCR) em gel de poliacrilamida 10\%. A) Reação de amplificação do gene de beta-globina e GP5/GP6; B) Identificação de HPV 6, utilizando primers específicos; C) Identificação de HPV 16, utilizando primers específicos; D) Identificação de HPV 18, utilizando primers específicos; E) Identificação de HPV 31, utilizando primers específicos PM = Maracdor de massa molecular de 100pb; F) Identificação de HPV 33, utilizando primers específicos $\mathrm{P}=$ Controle positivo com banda de 100 pb referente à amplificação de DNA de HPV 11 extraído de células HeLa; B = Controle negativo, sem DNA. 


\subsection{EXPRESSÃO IMUNOISTOQUÍMICA DAS PROTEÍNAS Galectina-3, PARP- 1 e bcl-2 PARA OS TIPOS DE CARCINOMA DE LARINGE.}

A interpretação qualitativa dos resultados imunoistoquímicos foi classificada como negativa, discreta, moderada ou intensa. No presente estudo, nós consideramos como sendo baixa expressão quando as biópsias de laringe foram negativas ou mostraram discreta imunomarcação. A expressão foi classificada como de alta expressão quando a imunomarcação mostrava moderada ou intensa, como mostra a Tabela 3.

Tabela 3. Distribuição da intensidade de marcação de Galectina-3, PARP1 e bcl-2 em carcinomas de laringe e em linfonodos cervicais com metástase.

\begin{tabular}{|c|c|c|c|c|c|c|}
\hline & \multicolumn{2}{|c|}{${\text { Galectina }-3^{\mathrm{a}}}$} & \multicolumn{2}{|c|}{ PARP-1 $^{b}$} & \multicolumn{2}{|c|}{ bcl-2 $2^{c}$} \\
\hline & $\mathbf{B E}$ & $\mathbf{A E}$ & $\mathbf{B E}$ & $\mathbf{A E}$ & $\mathbf{B E}$ & $\mathbf{A E}$ \\
\hline CLIS $(n=10)$ & 8 & 2 & 5 & 5 & 8 & 2 \\
\hline CLS (n=27) & 6 & 21 & 10 & 17 & 25 & 2 \\
\hline CLM (n=28) & 4 & 24 & 10 & 18 & 28 & 0 \\
\hline $\mathrm{LC}(\mathrm{n}=28)$ & 2 & 26 & 11 & 17 & 26 & 2 \\
\hline \multicolumn{7}{|c|}{ 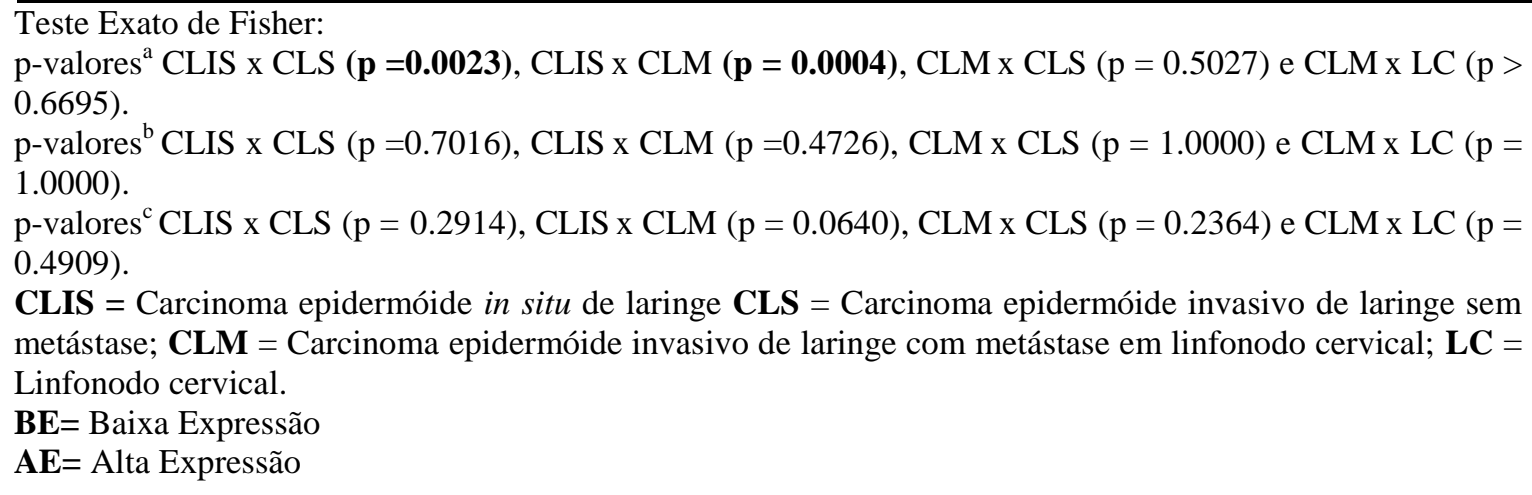 } \\
\hline
\end{tabular}


Podemos observar na Tabela 3 que a proteína PARP-1 apresentou uma homogeneidade de marcação tanto alta como baixa expressão entre os grupos de carcinoma de laringe e nos linfonodos metastáticos. Em relação à Galectina-3 observou um predomínio de casos com alta expressão. Já a proteína bcl-2 apresentou um predomínio de baixa expressão em todos os casos de carcinoma de laringe e seus respectivos linfonodos metastáticos.

Não houve diferença estatisticamente significante entre o padrão de marcação de, PARP-1 e bcl-2 entre os grupos CLIS, CLS, CLM e LC. No entanto foram observads diferenças estatísticas signifcantes quando comparados os padrões de expressão de galectina-3 entre os rupos CLIS ( $\mathrm{p}=0,0023)$ e CLIS versus CLM ( $\mathrm{p}=0,0004)$.

As figuras 7,8 e 9 mostram exemplos de padrão de imunomarcação das respectivas proteínas (galectina-3, PARP1 e bcl-2). 

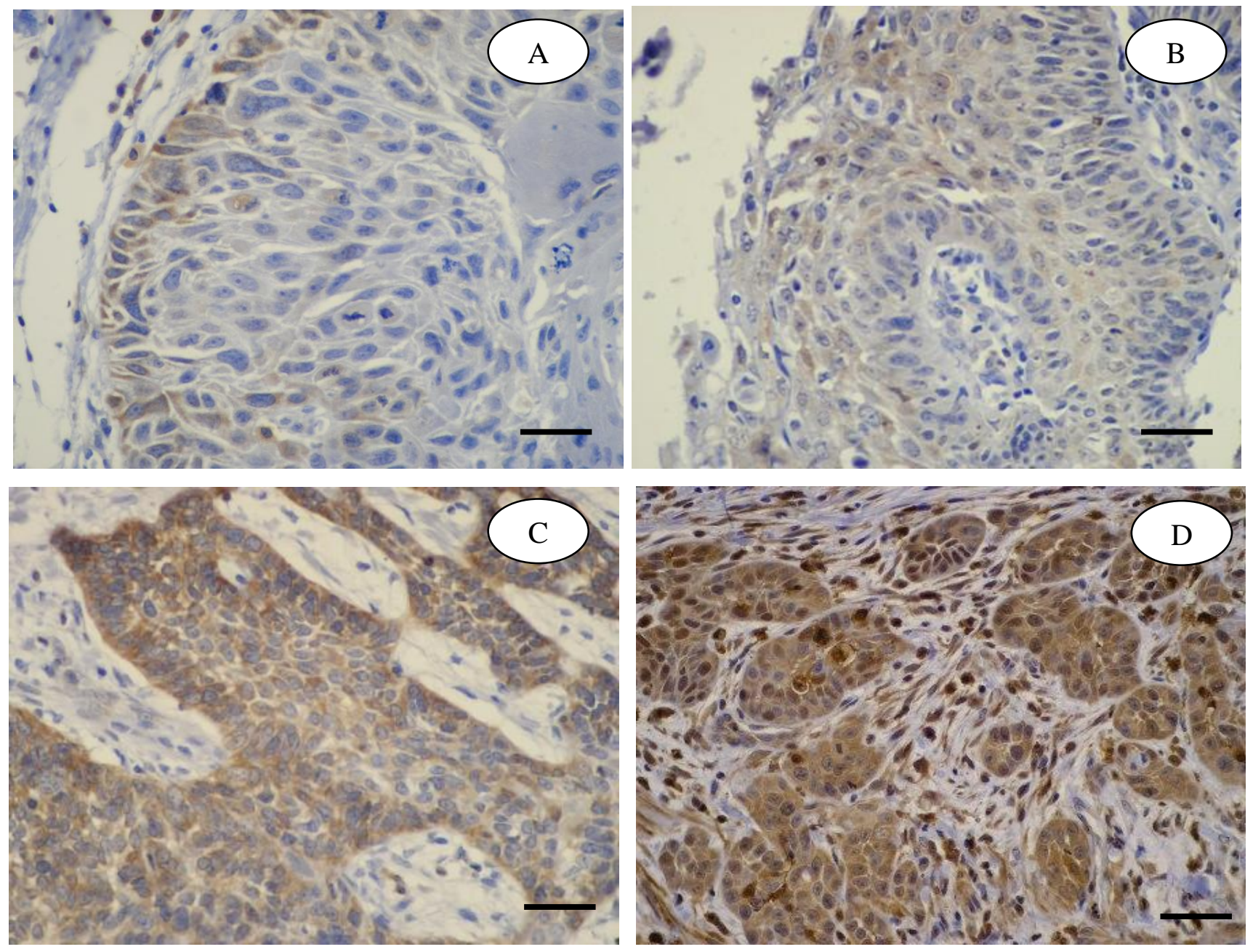

Figura 7. Imunomarcação para galectina-3. (A) Carcinoma de laringe in situ com marcação leve; (B) Carcinoma de laringe sem metástase com marcação moderada (C) Carcinoma com metástase de laringe com marcação intensa; (D) Linfonodo

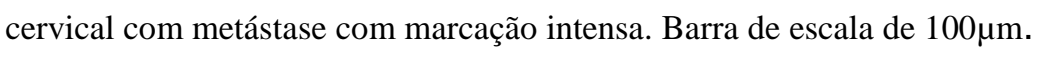



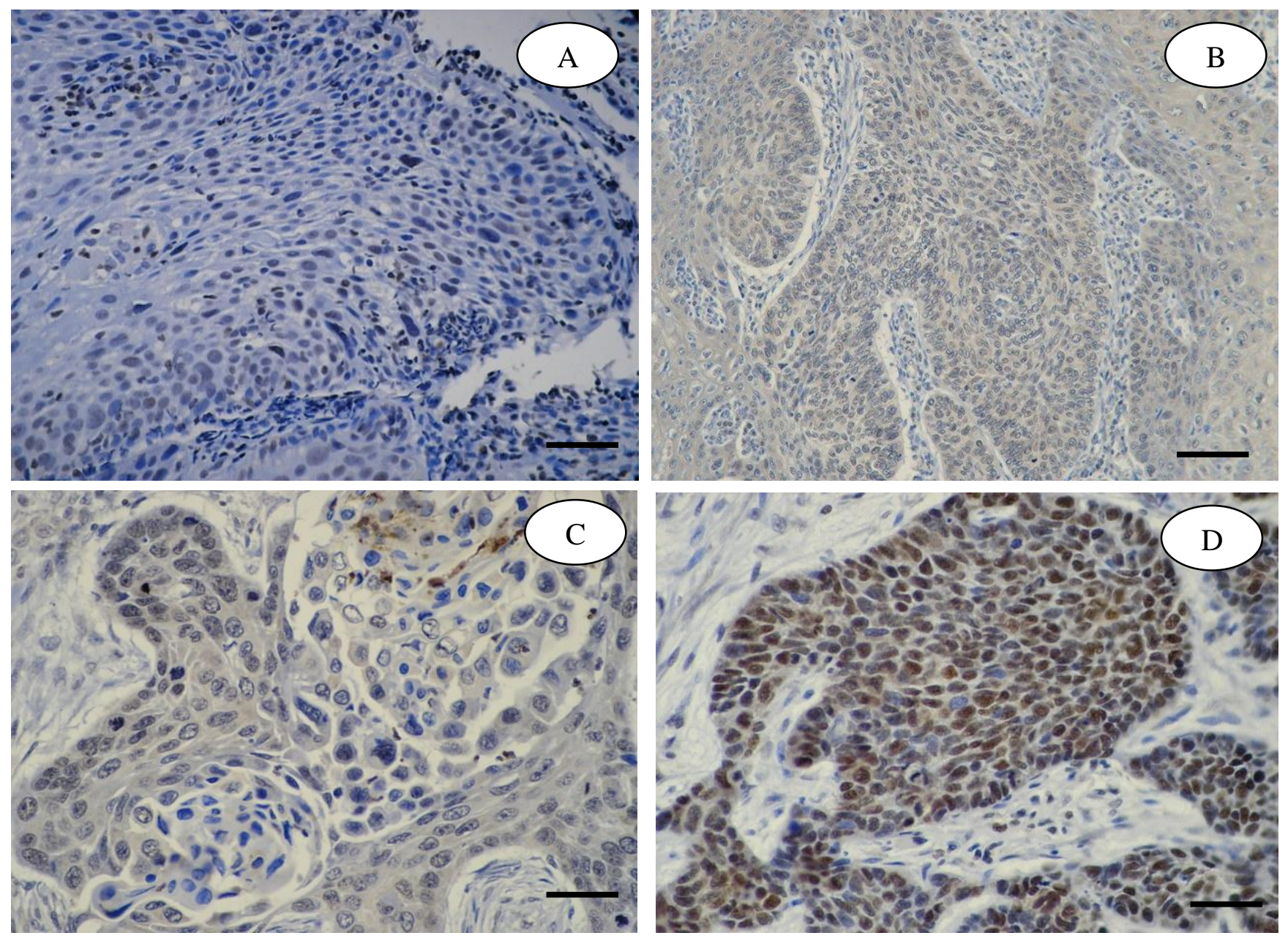

Figura 8. Imunomarcação para PARP-1. (A) Carcinoma de laringe in situ com marcação leve; (B) Carcinoma de laringe sem metástase com marcação moderada (C) Carcinoma com metástase de laringe com marcação moderada; (D) Linfonodo

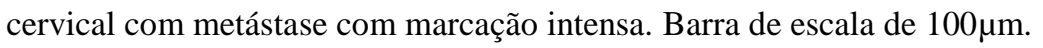



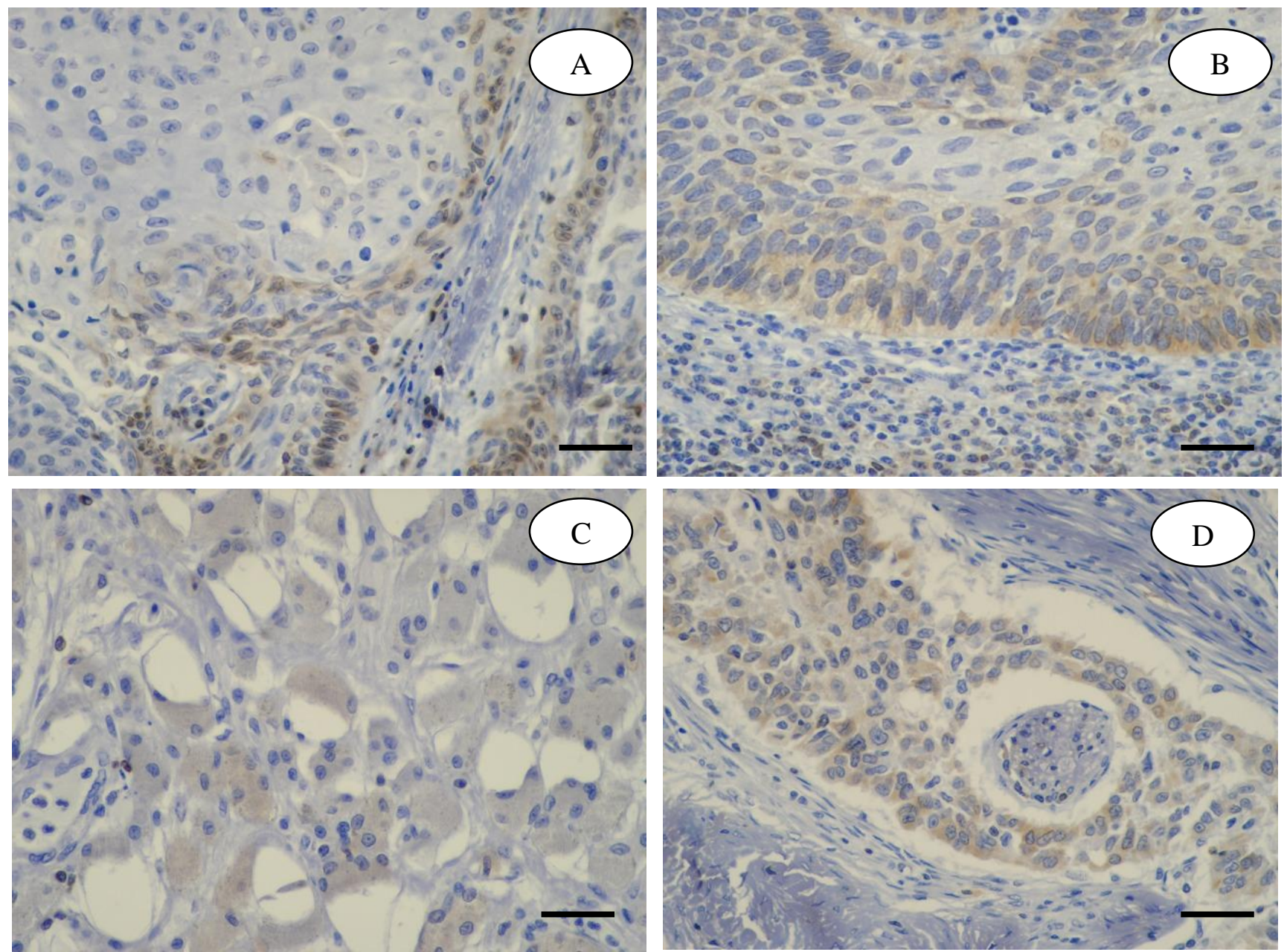

Figura 9. Imunomarcação para bcl-2. (A) Carcinoma de laringe in situ com marcação leve; (B) Carcinoma de laringe sem metástase com marcação leve (C) Carcinoma com metástase de laringe com marcação leve; (D) Linfonodo cervical com metástase com marcação moderada. Barra de escala de $100 \mu$ m. 
$\mathrm{Na}$ avaliação quantitativa de galectina-3 observamos um significativo aumento de expressão no carcinoma invasivo de laringe independente da presença ou ausência de metástase (CLS e CLM) quando comparado com carcinoma in situ de laringe (CLIS), ambas as comparações apresentando um p-valor $<0,05$. Para as proteínas PARP-1 e bcl2 não houve diferença nos níveis de expressão entre os grupos analisados. Níveis similares das proteínas bcl-2 foram verificados entre lesão primária com metástase (CLM) e seus respectivos linfonodos cervicais com metástase (LB). No entanto, através do método estatístic de Correlação de Sperman foi possível observar uma correlação positiva significante entre as expressões das lesões metastáticas com seus respectivos linfonodos tanto para galectina-3 $(\mathrm{p}<0,0001)$ quanto para PARP1 $(\mathrm{p}<0,0001)$ esquematizada na Tabela 4. 
Tabela 5. Imunoexpressão quantitativa de Galectina-3, PARP-1 e bcl-2 em carcinoma de laringe dividido de acordo com o diagnóstico histológico.

\begin{tabular}{|c|c|c|c|}
\hline & Galectina- $^{\mathrm{a}}$ & PARP-1 ${ }^{b}$ & $\mathrm{bcl}-2^{\mathrm{c}}$ \\
\hline & $\mathrm{M} \pm \mathrm{EP}$ & $\mathrm{M} \pm \mathrm{EP}$ & $\mathrm{M} \pm \mathrm{EP}$ \\
\hline CLIS $(n=10)$ & $36.0 \pm 10.30$ & $51,9 \pm 11,9$ & $22,9 \pm 7,82$ \\
\hline $\operatorname{CLS}(n=27)$ & $70.5 \pm 3.90$ & $69,17 \pm 3,48$ & $10,76 \pm 4,11$ \\
\hline CLM $(n=28)$ & $66.3 \pm 5.16$ & $60,95 \pm 4,37$ & $5,97 \pm 3,39$ \\
\hline $\mathrm{LC}(\mathrm{n}=28)$ & $61.5 \pm 4.50$ & $61,5 \pm 4,50$ & $2,27 \pm 1,73$ \\
\hline \multicolumn{4}{|c|}{ 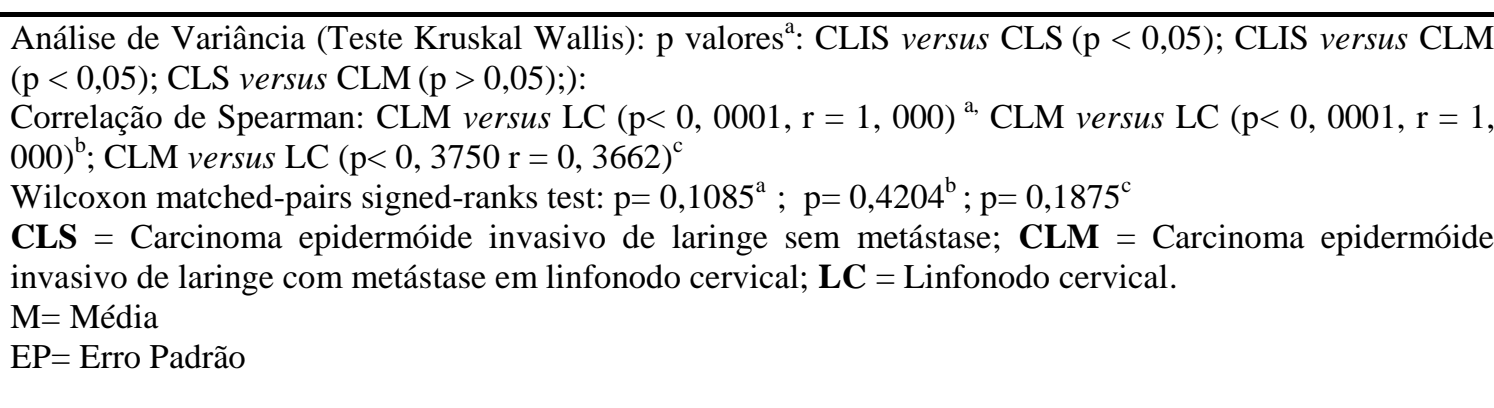 } \\
\hline
\end{tabular}

\subsection{HPV E EXPRESSÃO IMUNOISTOQUÍMICA de Galectina-3, PARP-1 e bcl-2}

Alta expressão de galectina-3 foi observada em $6(81,71 \%)$ de 7 pacientes HPV positivos com uma média de 56,93\% de células marcadas (Tabela 5). Para PARP-1 foi observado alta expressão em $3(42,85 \%)$ de 7 pacientes positivos para HPV, com uma média de 72,54\% de células marcadas. Em relação à proteína bcl-2 apenas $1(14,28 \%)$ dos 7 casos positivos apresentou positividade, mostrando uma baixa expressão.

No grupo de carcinomas de laringe HPV negativos altos níveis de galectina -3 e PARP-1 foram observados, uma média de 65,0\% e 62,30\% respectivamente. Já para a 
proteína bcl-2 foi observada uma prevalência de baixa expressão nos carcinomas de laringe sem HPV estudados.

Tabela 6. Expressão quantitativa de Galectina-3, PARP-1 e bcl22 relacionada com a presença de HPV e seus tipos em carcinomas de laringe.

\begin{tabular}{lccc}
\hline & Galectin-3 & PARP-1 & bcl-2 \\
\hline HPV positivo $(\mathrm{n}=7)$ & $\mathrm{M} \pm \mathrm{EP}$ & $\mathrm{M} \pm \mathrm{EP}$ & $\mathrm{M} \pm \mathrm{EP}$ \\
*HPV negativo $(\mathrm{n}=55)$ & $65,93 \pm 11,66$ & $72,54 \pm 1,42$ & $7,03 \pm 7,03$ \\
HPV 6 $(\mathrm{n}=1)$ & $73,1 \pm-$ & $62,30 \pm 3,28$ & $7,78 \pm 2,14$ \\
HPV18 $(\mathrm{n}=1)$ & $73,28 \pm-$ & - \\
HPV31 $(\mathrm{n}=1)$ & $7,877 \pm-$ & $76,59 \pm-$ & $49,26 \pm$ \\
$* *$ HPV Dois tipos & $58,20 \pm 11,14$ & $69,98 \pm 2,19$ & - \\
$(\mathrm{n}=4)$ & & & \\
\hline
\end{tabular}

(*) Em 10 (15.4\%) pacientes, o gene de beta-globina não foi amplificada, indicando degradação de DNA, e esses pacientes não foram considerados nem HPV positivo nem HPV negativo.

**HPV 31 e 33; HPV 6 e 16; HPV16 e 31 e HPV16 e 33

M= Média

$\mathrm{EP}=$ Erro Padrão 
Para que ocorra uma transição do epitélio normal de laringe para um carcinoma escamoso é preciso múltiplos estágios, sendo casualmente relacionado por acúmulos progressivos de alterações genéticas. Vários aspectos da carcinogênese da laringe vêm sendo intensivamente estudados, incluindo etiologia, classificação histológica, tratamento, frequiência de transformação maligna e fatores preditivos (Redondo, Esteban et al., 2006).

Entre os 65 pacientes estudados com carcinoma de laringe, observamos uma forte associação entre consumo de álcool e exposição ao tabaco, não havendo, entretanto, diferenças de consumo e exposição a esses agentes quando relacionados às lesões de carcinoma in situ e carcinoma invasivo com e sem metástase. Estudos epidemiológicos vêm, consistentemente, mostrando que consumo de álcool e exposição ao tabaco aumentam o risco de câncer de laringe (Altieri, Garavello et al., 2005). Bosara et al, (1999) analisaram 97 lesões displásicas da região de cabeça e pescoço, incluindo 47 casos de displasia de laringe, achando uma correlação direta entre o grau da displasia, transformação maligna e a quantidade de consumo de bebida e cigarros. Neuwirth-Riedl et al (2002) também chegaram às mesmas conclusões. Na Europa aproximadamente $87 \%$ dos casos de carcinomas de laringe são atribuídos ao uso de cigarros, sendo que $75 \%$ correspondem aos que ainda fumam e $12 \%$ aos ex-fumantes. (Hashibe, Boffetta et al., 2007).

Um estudo de caso controle realizado na cidade de São Paulo verificou um odds ratio de 7,5 para fumantes pesados e de 3,7 para consumidores de bebida (Sartor, 2003). Apesar do nosso estudo não determinar o número de cigarros consumidos ou a quantidade de bebida consumida, nós verificamos um odds ratio de 2,0 para quem foi 
exposto ao álcool e que tinha sido diagnosticado como carcinoma invasivo de laringe. Em adição, o odds ratio para quem foi exposto ao tabaco $(8,1$ para carcinoma invasivo de laringe) também foi bem similar ao observado no estudo citado anteriormente (Sartor, 2003). A maioria dos estudos concorda que fumantes e pessoas que abusam da bebida alcoólica, e especialmente uma combinação desses dois, compoem o grupo com maior predisposição para lesões e carcinomas de laringe (Gale, Michaels et al., 2008).

Nesse estudo houve uma predominância de pacientes brancos masculinos com uma média de idade de 59 anos. Esta média se apresenta dentro do intervalo de idade relatado por Goiato e colaboradores (2006) onde os 88 pacientes estudados com câncer de laringe se encontravam na faixa etária de 51 a 69 anos. Em um estudo realizado na Sérvia, a idade de 108 pacientes com câncer de laringe variou de 39 a 83 anos, com uma média de 60 anos (Zvrko, Gledovic et al., 2008). Carcinomas de laringe são principalmente limitados à população adulta e afeta mais homens do que mulheres. Essa disparidade é especialmente evidente após os 54 anos de idade (Gale et al, 2008). A relação entre homem e mulher quase 7:1, é mais alta para esse tipo de câncer do que em qualquer outro sítio, enfatizando a raridade de câncer de laringe nas mulheres (Filho, 2004).

Enquanto a relação entre câncer ano-genital e HPV já é claramente demonstrada, a função do HPV nos carcinomas de laringe não é muito clara e resultados contraditórios vêm sendo descritos (Lindeberg e Krogdahl, 1997; Jacob, Sreevidya et al., 2002; Morshed, Korobowicz et al., 2005). A prevalência desse vírus no carcinoma de laringe possui uma variância considerável, entre $0 \%$ a 54,1\%, dependendo da população estudada, tipo da espécie analisada (amostras congeladas incluídos em 
parafinas e a fresco) e o método de detecção (Gale, Michaels et al., 2008). Utilizando a técnica de hibridização in situ, Brito Vassallo et al. (2000) encontraram DNA do HPV em 4/45 $(8,8 \%)$ de casos de carcinoma invasivo de laringe. Já quando a técnica de Southern blot foi utilizada, Scheurlen e colaboradores (1986) detectaram 3\% de positividade para HPV. Enquanto Watts, Brewer et al, (1991) detectaram o vírus em $11 \%$ dos casos.

A técnica de PCR vem sendo utilizada por vários autores para a detecção do HPV em carcinomas de laringe. Guvenç et al (2008) detectaram o HPV em 7 de 50 pacientes (14\%), muito semelhante a Silva et al (2008) quando detectaram o DNA do HPV em 5 de 20 casos de biópsias de laringe.

Em nosso estudo, onde utilizamos a técnica de PCR, apenas 7 de 55 pacientes positivos para beta globina foram positivos para HPV, sendo encontrados os tipos 6, 16, 18, 31 e 33. Esse resultado suporta que a função do HPV nos tumores de cabeça e pescoço é mais importante do que nos tumores de laringe (Koskinen, Brondbo et al., 2007). Até agora a evidência da ligação do HPV como o carcinoma de laringe é considerada incompleta (Gale, Michaels et al., 2008).

A laringe faz parte da região de cabeça e pescoço, e, devido às várias particularidades clínicas e moleculares, ela é classificada separadamente da cavidade oral e da faringe (Jemal, Tiwari et al., 2004). O processo de carcinogênese na laringe é baseado no acúmulo de vários estágios de danos genéticos, que freqüentemente afetam genes envolvidos na regulação do ciclo celular (Bartkova, Lukas et al., 1995). Devido a essas particularidades os vários tipos de marcadores moleculares podem se expressar 
diferentemente na laringe quando comparada a outros sítios da região da cabeça e pescoço (Kaskayasi et al, 2001).

Um dos tipos de marcadores que vem sendo muito estudado, tanto no câncer de cabeça e pescoço como no câncer de laringe, é a galectina-3. Estudos prévios demonstraram uma forte associação entre uma alta expressão de galectina-3 e uma maior agressividade nos tumores de cabeça e pescoço (Saussez, Camby et al., 2007).

Sendo uma proteína monomérica com efeito multifuncional e com alta afinidade por beta-galactosidases, a galectina-3 possui uma atividade que inclui a modulação de adesão célula-célula e célula a MEC ( Matriz Extracelular), além de participar na regulação da proliferação e apoptose celular (Saussez, Camby et al., 2007 Wang, 2004). Nos vários tipos de células neoplásicas a galectina-3 exerce diferentes funções, desempenhando um importante papel na tumorogênese e metástase (Puglisi, Minisini et al., 2004).

Neste trabalho, nós observamos uma alta intensidade e grande número de células expressando galectina-3, o que pode indicar indicando uma estreita relação entre super expressão de galectina-3 e câncer invasivo de laringe.

Piantelli et al. (2002) observaram que a associação da expressão dessa proteína parece ser positiva com ceratinização e grau histológico do tumor e uma correlação significante foi vista entre positividade de galectina-3 no tumor, metástase a distância e uma sobrevida dos pacientes. Huseyin et al. (2008) observaram uma diminuição da expressão de galectina-3 nos tumores de tireóide com metástase em linfonodos, indicando uma baixa regulação na progressão desse tipo de câncer. 
Galectina-3 recombinante parece afetar a mobilidade das células tumorais influenciando sua capacidade de invasão in vitro. Porém tanto o efeito positivo como negativo dessa proteína vem sendo descrito (Le Marer e Hughes, 1996; Moisa, Fritz et al., 2007). Provavelmente, devido a diferentes fenótipos de cada tumor e pelos efeitos multifatoriais da galectina-3 em células tumorais, existam tantos trabalhos controversos em relação à progressão tumoral e expressão de galectina-3 (Sanjuan, Fernandez et al., 1997; Song, Billiar et al., 2002).

Apesar da galectina-3 ser associada a diversos mecanismos biológicos envolvidos com o desenvolvimento e progressão tumoral, na maioria dos tipos de tumores já estuddos, o efeito da galectina-3 é de promoção tumoral. Por isso, inibidores de galectina-3 podem ser úteis no tratamento de vários tipos de câncer suprimindo os vários mecanismos dessa proteína no desenvolvimento do mesmo (Yang, Rabinovich et al., 2008).

Outra proteína que tem o papel biológico bastante complexo e que engloba muitas funções é a PARP-1. Ela vem sendo descrita como uma proteína de reparo do DNA e de manutenção da integridade genômica, uma vez que trabalha como um sensor de danos do DNA se ligando em regiões onde há quebras simples ou dupla do mesmo (Nguewa, Fuertes et al., 2003).

PARP-1 é expressa em todas as células nucleadas humanas, exceto em neutrófilos e a alta expressão dessa proteína vem sendo descrita em certos tipos de cânceres humanos (Drew e Calvert, 2008).

Neste trabalho observamos uma alta expressão de PARP-1 nos carcinomas invasivos de laringe sem e com metástase e em seus linfonodos. Não houve diferença 
estatisticamente significante ao comparar a expressão da proteína com os diferentes tipos de lesões estudadas. Além disso, podemos considerar o valor percentual de células marcadas com PARP-1 aproximadamente constante para os carcinomas invasivos.

A atividade de PARP-1 pode mostrar uma correlação inversa com um grau de diferenciação celular de modo que, a maioria dos tumores apresentaria um acelerado metabolismo de PARP-1 (Nguewa, Fuertes et al., 2003). Shiobara et al. (2001), por exemplo, observaram um aumento da atividade dessa proteína tanto em tumores hepatocelulares e linfoma não Hodgkin de baixo grau quando comparados a de células de fígado e a linfócitos saudáveis.

Staibano et al. (2005) encontram uma significante correlação entre a alta expressão de PARP-1 e invasão vertical na fase de crescimento dos melanomas. Aumento de expressão de PARP-1 vem sendo descrito em vários tipos de cânceres tais como: linfoma, carcinoma de mama, sarcoma de Ewing, carcinoma hepatocelular e câncer endometrial (Nosho, Yamamoto et al., 2006). Já a baixa expressão de PARP-1 em câncer de mama foi correlacionado com uma maior instabilidade genômica (Masutani, Nakagama et al., 2003). Expressão de gene de PARP-1 em linhagens celulares de câncer gástrico, câncer de colo e leucemia de células T vem sendo descritos na literatura como substancialmente mais baixa do que em outros tipos de linhagens de células cancerosas (Masutani, Nakagama et al., 2003).

Segundo Feleszko et al. (2002) e Nguewa et al. (2003) a inibição da atividade de PARP-1 é uma promissora estratégia para melhorar o resultado de terapias citotóxicas em diferentes tipos de tumores. 
De acordo com Ciavanttini et al. (1999) a proteína bcl-2 também participa do controle do ciclo celular, especialmente, relacionado com a morte celular programada, denominada apoptose.

A proteína bcl-2 é um dos genes que regula a apoptose, sendo responsável por codificar uma proteína localizada nas membranas plasmáticas, do retículo endoplasmático e das mitocôndrias (Gillet e Brun, 1996; Letai, 2008). Em sua forma complexada, a proteína bcl-2 é capaz de prevenir a morte celular em diversas situações (Plas e Thompson, 2002; Zhang, Shi et al., 2005).

Estudos anteriores demonstraram que o aumento da expressão de bcl-2 poderia ser um bom marcador prognóstico em vários tipos de câncer, tais como o câncer de mama, de ovário, cervical e linfoma (Crawford, Caldwell et al., 1998; Dimitrakakis, Kymionis et al., 2000). Outros, entretanto, verificaram a ausência de expressão dessa proteína em lesões orais que evoluíram para o câncer (Chang, Su et al., 2002), e ainda baixos níveis no carcinoma cervical microinvasor (Kohlberger, Edwards et al., 2003). Entretanto, o prognóstico da expressão de bcl-2 em carcinoma de laringe vem sendo descrito com resultados variáveis (Redondo, Esteban et al., 2006). Em todas as biópsias analisadas no presente estudo $(\mathrm{n}=93)$ observamos, na maioria dos casos $(93,54 \%)$, uma alta incidência de negatividade na expressão imunoistoquímica de bcl-2. Em relação à progressão,comparando os padrões de expressão entre os grupos estudados, não foi observada diferença estatisticamente significante entre a intensidade da marcação e o número de células marcadas.

Vários autores descreveram em seus estudos uma alta incidência de expressão da proteína bcl-2 em carcinoma de laringe (Whisler, Wood et al., 1998; Yuen, Lam et al., 
2001; Teni, Pawar et al., 2002; Trask, Wolf et al., 2002) e a expressão dessa proteína foi correlacionada com o grau de diferenciação. Foi relatado um significante aumento da expressão em tumores pouco diferenciado quando comparados com os tumores bem diferenciados de laringe (Whisler, Wood et al., 1998; Yuen, Lam et al., 2001; Redondo, Esteban et al., 2006). Entretanto Jordan e colaboradores (2002) observaram que a expressão de bcl-2 está associada a carcinomas orais pouco diferenciados, assim como Teni et al. (2002) demonstraram essa associação em carcinomas de esôfago e de tireóide.

No presnte estudo, não foram realizadas associações entre prognóstico e expressão de bcl-2, porém, vários autores descrevem uma associação entre alta expressão de bcl-2 e aumento de sobrevida em pacientes com câncer de laringe (Xie, Clausen et al., 1999; Homma, Furuta et al., 2001). Por outro lado, alguns estudos não acharam nenhuma relação entre bcl-2 e prognóstico (Hirvikoski, Kumpulainen et al., 1999; Friedman, Lim et al., 2001).

Vários autores vêm estudando o efeito da presença do HPV no câncer associado à desregulação de algumas proteínas entre elas o bcl-2 e PARP-1 (Hockenbery, Nunez et al., 1990; Kerr, Winterford et al., 1994; Syrjanen e Syrjanen, 1999; Lee, Kim et al., 2002; Wsierska-Gadek e Horky, 2003). Entretanto, devido ao baixo número de amostras positivas para HPV $(n=7)$ observados em nosso estudo não foi possível comparar o comportamento dessas proteínas quanto aos tipos de HPV presentes. 
6.1. Os parâmetros sexo, idade, fumo e álcool foram homogêneos entre a população de carcinomas invasivos de laringe com e sem metástase.

6.1.2. Confirmou-se a maior incidência de carcinoma de laringe com e sem metástase no sexo masculino e para indivíduos que consumem álcool e cigarros com idade média de 56 a 59 anos.

6.2. A taxa de detecção do HPV na população estudada foi de $7.4 \%$. A discrepância observada entre as porcentagens dos trabalhos pode estar relacionada com a variação de sensibilidade do método utilizado e com a diversidade populacional estudada.

6.2.1 Os tipos de HPV presentes nas amostras analisadas foram HPV 6, 16, 31 e 33. Os HPVs 11 e 18 não foram encontrados.

6.3. A progressão do carcinoma de laringe foi associada ao aumento da expressão imunoistoquímica de galectina-3, indicando que essa proteína poderia ser considerada um bom marcador da evolução maligna e metástase no carcinoma de laringe.

6.4 Não foram encontradas associações entre a expressão de PARP-1 e os carcinomas de laringe estudados, sugerindo que esta proteína não poderia ser considerada como um marcador da progressão maligna no câncer de laringe. 
6.5 Não foram encontradas associações entre a expressão de bcl-2 e os carcinomas de laringe estudados, sugerindo que esta proteína não poderia ser considerada como um marcador da progressão maligna no câncer de laringe.

6.6 Não foi possível verificar quaisquer correlações entre as proteínas Galectina-3, bcl-2 e PARP-1 e o HPV devido ao baixo índice de casos positivos. 
Ahmed, H., P. P. Banerjee, et al. Differential expression of galectins in normal, benign and malignant prostate epithelial cells: silencing of galectin-3 expression in prostate cancer by its promoter methylation. Biochem Biophys Res Commun, v.358, n.1, Jun 22, p.2416. 2007.

Alberts, B. e R. M. May. Scientist support for biological weapons controls. Science, v.298, n.5596, Nov 8, p.1135. 2002.

Almadori, G., F. Bussu, et al. Molecular markers in laryngeal squamous cell carcinoma: towards an integrated clinicobiological approach. Eur J Cancer, v.41, n.5, Mar, p.68393. 2005.

Altieri, A., W. Garavello, et al. Alcohol consumption and risk of laryngeal cancer. Oral Oncol, v.41, n.10, Nov, p.956-65. 2005.

Atula, S., R. Grenman, et al. Detection of human papillomavirus (HPV) in laryngeal carcinoma cell lines provides evidence for a heterogeneic cell population. Eur J Cancer, v.35, n.5, May, p.825-32. 1999.

Bartkova, J., J. Lukas, et al. Abnormal patterns of D-type cyclin expression and G1 regulation in human head and neck cancer. Cancer Res, v.55, n.4, Feb 15, p.949-56. 1995.

Bartolazzi, A., A. Gasbarri, et al. Application of an immunodiagnostic method for improving preoperative diagnosis of nodular thyroid lesions. Lancet, v.357, n.9269, May 26, p.1644-50. 2001.

Ben-Ezra, J. M., M. J. Kornstein, et al. Small cell carcinomas of the lung express the Bcl-2 protein. Am J Pathol, v.145, n.5, Nov, p.1036-40. 1994.

Bergero, N., R. De Pompa, et al. Galectin-3 expression in parathyroid carcinoma: immunohistochemical study of 26 cases. Hum Pathol, v.36, n.8, Aug, p.908-14. 2005.

Bettini, J. S., E. G. Soares, et al. PCR diagnosis of HPV in cervical biopsies of CIN and invasive neoplasia formerly diagnosed as HPV negative. Acta Cytol, v.47, n.4, Jul-Aug, p.545-9. 2003.

Bieche, I., G. De Murcia, et al. Poly(ADP-ribose) polymerase gene expression status and genomic instability in human breast cancer. Clin Cancer Res, v.2, n.7, Jul, p.1163-7. 1996.

Bonfiglio, T. A. Diagnostic cytology of the uterine cervix: a major contribution and classic reference in gynecologic cytopathology. Cancer, v.81, n.6, Dec 25, p.324-7. 1997. 
Bouchard, V. J., M. Rouleau, et al. PARP-1, a determinant of cell survival in response to DNA damage. Exp Hematol, v.31, n.6, Jun, p.446-54. 2003.

Brasil, M. D. S. D. INSTITUTO NACIONAL DE CÂNCER DO MINISTÉRIO DA SAUDE (INCA) 2008.

Brito, H., J. Vassallo, et al. Detection of human papillomavirus in laryngeal squamous dysplasia and carcinoma. An in situ hybridization and signal amplification study. Acta Otolaryngol, v.120, n.4, Jun, p.540-4. 2000.

Chang, K. C., I. J. Su, et al. Pathological features of betel quid-related oral epithelial lesions in taiwan with special emphasis on the tumor progression and human papillomavirus association. Oncology, v.63, n.4, p.362-9. 2002.

Chang, P., M. K. Jacobson, et al. Poly(ADP-ribose) is required for spindle assembly and structure. Nature, v.432, n.7017, Dec 2, p.645-9. 2004.

Cheah, P. L. e L. M. Looi. Biology and pathological associations of the human papillomaviruses: a review. Malays J Pathol, v.20, n.1, Jun, p.1-10. 1998.

Chin, D., G. M. Boyle, et al. Head and neck cancer: past, present and future. Expert Rev Anticancer Ther, v.6, n.7, Jul, p.1111-8. 2006.

Ciavattini, A., G. Lucarini, et al. bcl-2 protein expression in cervical intraepithelial neoplasia: no evidence of a prognostic significance in mild and moderate lesions. Anticancer Res, v.19, n.6B, Nov-Dec, p.5463-7. 1999.

Colombel, M., F. Symmans, et al. Detection of the apoptosis-suppressing oncoprotein bc1-2 in hormone-refractory human prostate cancers. Am J Pathol, v.143, n.2, Aug, p.390-400. 1993.

Crawford, R. A., C. Caldwell, et al. Prognostic significance of the bcl-2 apoptotic family of proteins in primary and recurrent cervical cancer. Br J Cancer, v.78, n.2, Jul, p.210-4. 1998.

De Villiers, E. M. Papillomavirus and HPV typing. Clin Dermatol, v.15, n.2, Mar-Apr, p.199206. 1997.

De Villiers, E. M., C. Fauquet, et al. Classification of papillomaviruses. Virology, v.324, n.1, Jun 20, p.17-27. 2004.

Dimitrakakis, C., G. Kymionis, et al. The possible role of p53 and bcl-2 expression in cervical carcinomas and their premalignant lesions. Gynecol Oncol, v.77, n.1, Apr, p.129-36. 2000. 
Dosemeci, M., I. Gokmen, et al. Tobacco, alcohol use, and risks of laryngeal and lung cancer by subsite and histologic type in Turkey. Cancer Causes Control, v.8, n.5, Sep, p.729-37. 1997.

Drew, Y. e H. Calvert. The potential of PARP inhibitors in genetic breast and ovarian cancers. Ann N Y Acad Sci, v.1138, Sep, p.136-45. 2008.

Du, L., X. Zhang, et al. Intra-mitochondrial poly(ADP-ribosylation) contributes to NAD+ depletion and cell death induced by oxidative stress. J Biol Chem, v.278, n.20, May 16, p.18426-33. 2003.

Dumic, J., S. Dabelic, et al. Galectin-3: an open-ended story. Biochim Biophys Acta, v.1760, n.4, Apr, p.616-35. 2006.

Duriez, P. J. e G. M. Shah. Cleavage of poly(ADP-ribose) polymerase: a sensitive parameter to study cell death. Biochem Cell Biol, v.75, n.4, p.337-49. 1997.

Dyson, N., K. Buchkovich, et al. Cellular proteins that are targetted by DNA tumor viruses for transformation. Princess Takamatsu Symp, v.20, p.191-8. 1989.

El-Deiry, W. S., J. W. Harper, et al. WAF1/CIP1 is induced in p53-mediated G1 arrest and apoptosis. Cancer Res, v.54, n.5, Mar 1, p.1169-74. 1994.

El-Serag, H. B., E. J. Hepworth, et al. Gastroesophageal reflux disease is a risk factor for laryngeal and pharyngeal cancer. Am J Gastroenterol, v.96, n.7, Jul, p.2013-8. 2001.

Feleszko, W., I. Mlynarczuk, et al. Lovastatin potentiates antitumor activity of doxorubicin in murine melanoma via an apoptosis-dependent mechanism. Int J Cancer, v.100, n.1, Jul 1, p.111-8. 2002.

Ferlay, J. B., F.; Pizani, P.; Parkin, D.M. Globocan 2000: Cancer incidence, mortality and prevalence worldwide. 2001.

Filho, V. W. The epidemiology of laryngeal cancer in Brazil. São Paulo Medical Journal Revista Paulista de Medicina. 2004.

Friedman, M., J. W. Lim, et al. Prognostic significance of Bcl-2 and p53 expression in advanced laryngeal squamous cell carcinoma. Head Neck, v.23, n.4, Apr, p.280-5. 2001.

Gale, N., L. Michaels, et al. Current review on squamous intraepithelial lesions of the larynx. Histopathology, Aug 25. 2008.

Garavello, W., L. Giordano, et al. Diet diversity and the risk of oral and pharyngeal cancer. Eur J Nutr, v.47, n.5, Aug, p.280-4. 2008. 
Ghabreau, L., J. P. Roux, et al. Poly(ADP-ribose) polymerase-1, a novel partner of progesterone receptors in endometrial cancer and its precursors. Int J Cancer, v.109, n.3, Apr 10, p.317-21. 2004.

Giermasz, A., M. Makowski, et al. Potentiating antitumor effects of a combination therapy with lovastatin and butyrate in the Lewis lung carcinoma model in mice. Int J Cancer, v.97, n.6, Feb 20, p.746-50. 2002.

Gillet, G. e G. Brun. Viral inhibition of apoptosis. Trends Microbiol, v.4, n.8, Aug, p.312-7. 1996.

Gillison, M. L. e K. V. Shah. Human papillomavirus-associated head and neck squamous cell carcinoma: mounting evidence for an etiologic role for human papillomavirus in a subset of head and neck cancers. Curr Opin Oncol, v.13, n.3, May, p.183-8. 2001.

Gorgoulis, V. G., P. Zacharatos, et al. Human papilloma virus (HPV) is possibly involved in laryngeal but not in lung carcinogenesis. Hum Pathol, v.30, n.3, Mar, p.274-83. 1999.

Grace, V. M., J. V. Shalini, et al. Co-overexpression of p53 and bcl-2 proteins in HPV-induced squamous cell carcinoma of the uterine cervix. Gynecol Oncol, v.91, n.1, Oct, p.51-8. 2003.

Guvenc, M. G., K. Midilli, et al. Detection of HHV-8 and HPV in laryngeal carcinoma. Auris Nasus Larynx, v.35, n.3, Sep, p.357-62. 2008.

Hanada, M., D. Delia, et al. bcl-2 gene hypomethylation and high-level expression in B-cell chronic lymphocytic leukemia. Blood, v.82, n.6, Sep 15, p.1820-8. 1993.

Hashibe, M., P. Boffetta, et al. Contribution of tobacco and alcohol to the high rates of squamous cell carcinoma of the supraglottis and glottis in Central Europe. Am J Epidemiol, v.165, n.7, Apr 1, p.814-20. 2007.

Heise, A. The clinical significance of HPV. Nurse Pract, v.28, n.10, Oct, p.8-19; quiz 20-1. 2003.

Herrero, R., X. Castellsague, et al. Human papillomavirus and oral cancer: the International Agency for Research on Cancer multicenter study. J Natl Cancer Inst, v.95, n.23, Dec 3, p.1772-83. 2003.

Hirvikoski, P., E. Kumpulainen, et al. Enhanced apoptosis correlates with poor survival in patients with laryngeal cancer but not with cell proliferation, bcl-2 or p53 expression. Eur J Cancer, v.35, n.2, Feb, p.231-7. 1999. 
Hockenbery, D., G. Nunez, et al. Bcl-2 is an inner mitochondrial membrane protein that blocks programmed cell death. Nature, v.348, n.6299, Nov 22, p.334-6. 1990.

Hockenbery, D. M. The bcl-2 oncogene and apoptosis. Semin Immunol, v.4, n.6, Dec, p.413-20. 1992.

Homma, A., Y. Furuta, et al. Correlation of clinicopathological parameters and biological markers related to apoptosis and proliferative activity with a clinical outcome in squamous cell carcinoma of the larynx treated with concurrent chemoradiotherapy. Auris Nasus Larynx, v.28 Suppl, May, p.S87-94. 2001.

Inohara, H., S. Akahani, et al. Galectin-3 stimulates cell proliferation. Exp Cell Res, v.245, n.2, Dec 15, p.294-302. 1998.

Ioffe, O. B., J. C. Papadimitriou, et al. Correlation of proliferation indices, apoptosis, and related oncogene expression (bcl-2 and c-erbB-2) and p53 in proliferative, hyperplastic, and malignant endometrium. Hum Pathol, v.29, n.10, Oct, p.1150-9. 1998.

Iwasawa, A., P. Nieminen, et al. Human papillomavirus in squamous cell carcinoma of the vulva by polymerase chain reaction. Obstet Gynecol, v.89, n.1, Jan, p.81-4. 1997.

Jackson, S., C. Harwood, et al. Role of Bak in UV-induced apoptosis in skin cancer and abrogation by HPV E6 proteins. Genes Dev, v.14, n.23, Dec 1, p.3065-73. 2000.

Jacob, S. E., S. Sreevidya, et al. Cellular manifestations of human papillomavirus infection in laryngeal tissues. J Surg Oncol, v.79, n.3, Mar, p.142-50. 2002.

Jemal, A., R. C. Tiwari, et al. Cancer statistics, 2004. CA Cancer J Clin, v.54, n.1, Jan-Feb, p.829. 2004.

Kerr, J. F., C. M. Winterford, et al. Apoptosis. Its significance in cancer and cancer therapy. Cancer, v.73, n.8, Apr 15, p.2013-26. 1994.

Koh, D. W., T. M. Dawson, et al. Poly(ADP-ribosyl)ation regulation of life and death in the nervous system. Cell Mol Life Sci, v.62, n.7-8, Apr, p.760-8. 2005.

Kohlberger, P., L. Edwards, et al. Microinvasive squamous cell carcinoma of the cervix: immunohistochemically detected prognostic factors in a case with poor clinical outcome. Gynecol Oncol, v.90, n.2, Aug, p.443-5. 2003.

Korsmeyer, S. J. BCL-2 gene family and the regulation of programmed cell death. Cancer Res, v.59, n.7 Suppl, Apr 1, p.1693s-1700s. 1999. 
Koskinen, W. J., K. Brondbo, et al. Alcohol, smoking and human papillomavirus in laryngeal carcinoma: a Nordic prospective multicenter study. J Cancer Res Clin Oncol, v.133, n.9, Sep, p.673-8. 2007.

Kurvinen, K., K. Syrjanen, et al. p53 and bcl-2 proteins as prognostic markers in human papillomavirus-associated cervical lesions. J Clin Oncol, v.14, n.7, Jul, p.2120-30. 1996.

Lautier, D., J. Lagueux, et al. Molecular and biochemical features of poly (ADP-ribose) metabolism. Mol Cell Biochem, v.122, n.2, May 26, p.171-93. 1993.

Lavin, C. W. e C. A. Mckeown. The oculocerebrorenal syndrome of Lowe. Int Ophthalmol Clin, v.33, n.2, Spring, p.179-91. 1993.

Le Marer, N. e R. C. Hughes. Effects of the carbohydrate-binding protein galectin-3 on the invasiveness of human breast carcinoma cells. J Cell Physiol, v.168, n.1, Jul, p.51-8. 1996.

Lee, D., J. W. Kim, et al. Functional interaction between human papillomavirus type 18 E2 and poly(ADP-ribose) polymerase 1. Oncogene, v.21, n.38, Aug 29, p.5877-85. 2002.

Letai, A. G. Diagnosing and exploiting cancer's addiction to blocks in apoptosis. Nat Rev Cancer, v.8, n.2, Feb, p.121-32. 2008.

Levi, F., C. La Vecchia, et al. Cancer incidence and mortality in Europe, 1983-87. Soz Praventivmed, v.38 Suppl 3, p.S155-229. 1993.

Li, X. e P. Coffino. High-risk human papillomavirus E6 protein has two distinct binding sites within p53, of which only one determines degradation. J Virol, v.70, n.7, Jul, p.4509-16. 1996.

Liang, X. H., S. Mungal, et al. Bcl-2 protooncogene expression in cervical carcinoma cell lines containing inactive p53. J Cell Biochem, v.57, n.3, Mar, p.509-21. 1995.

Lindeberg, H. e A. Krogdahl. Laryngeal dysplasia and the human papillomavirus. Clin Otolaryngol Allied Sci, v.22, n.4, Aug, p.382-6. 1997.

Liu, F. T., R. J. Patterson, et al. Intracellular functions of galectins. Biochim Biophys Acta, v.1572, n.2-3, Sep 19, p.263-73. 2002.

Manos, M. M., Y. Ting, et al. The use of polymerase chain reaction amplification for the detection of genital humam papillomaviruses. In: M. Furth e M. Greaves (Ed.). In Molecular Diagnostics of Human Cancer: Cancer Cells. New York: Cold Spring Harbor Laboratory, v.7, 1989. The use of polymerase chain reaction amplification for the detection of genital humam papillomaviruses., p.209-214 
Masutani, M., H. Nakagama, et al. Poly(ADP-ribose) and carcinogenesis. Genes Chromosomes Cancer, v.38, n.4, Dec, p.339-48. 2003.

Poly(ADP-ribosyl)ation in relation to cancer and autoimmune disease. Cell Mol Life Sci, v.62, n.7-8, Apr, p.769-83. 2005.

Matarrese, P., N. Tinari, et al. Galectin-3 overexpression protects from cell damage and death by influencing mitochondrial homeostasis. FEBS Lett, v.473, n.3, May 19, p.311-5. 2000.

Mcglennen, R. C. Human papillomavirus oncogenesis. Clin Lab Med, v.20, n.2, Jun, p.383-406. 2000.

Miyashita, T., S. Krajewski, et al. Tumor suppressor p53 is a regulator of bcl-2 and bax gene expression in vitro and in vivo. Oncogene, v.9, n.6, Jun, p.1799-805. 1994.

Moisa, A., P. Fritz, et al. Growth/adhesion-regulatory tissue lectin galectin-3: stromal presence but not cytoplasmic/nuclear expression in tumor cells as a negative prognostic factor in breast cancer. Anticancer Res, v.27, n.4B, Jul-Aug, p.2131-9. 2007.

Mork, J., A. K. Lie, et al. Human papillomavirus infection as a risk factor for squamous-cell carcinoma of the head and neck. N Engl J Med, v.344, n.15, Apr 12, p.1125-31. 2001.

Morshed, K., E. Korobowicz, et al. Immunohistochemical demonstration of multiple HPV types in laryngeal squamous cell carcinoma. Eur Arch Otorhinolaryngol, v.262, n.11, Nov, p.917-20. 2005.

Muir, C. e L. Weiland. Upper aerodigestive tract cancers. Cancer, v.75, n.1 Suppl, Jan 1, p.14753. 1995.

Munger, K. e P. M. Howley. Human papillomavirus immortalization and transformation functions. Virus Res, v.89, n.2, Nov, p.213-28. 2002.

Nguewa, P. A., M. A. Fuertes, et al. Pharmacological modulation of Poly(ADP-ribose) polymerase-mediated cell death: exploitation in cancer chemotherapy. Mol Pharmacol, v.64, n.5, Nov, p.1007-14. 2003.

Nosho, K., H. Yamamoto, et al. Overexpression of poly(ADP-ribose) polymerase-1 (PARP-1) in the early stage of colorectal carcinogenesis. Eur J Cancer, v.42, n.14, Sep, p.2374-81. 2006.

Ochieng, J., B. Green, et al. Modulation of the biological functions of galectin-3 by matrix metalloproteinases. Biochim Biophys Acta, v.1379, n.1, Jan 8, p.97-106. 1998. 
Otero, U. B., B. N. Antoniazzi, et al. [Screening methodology application to evaluate cancer mortality in selected cities in the State of Minas Gerais, Brazil]. Cad Saude Publica, v.23 Suppl 4, p.S537-48. 2007.

Parker, S. L., T. Tong, et al. Cancer statistics, 1996. CA Cancer J Clin, v.46, n.1, Jan-Feb, p.527. 1996.

Parkin, D. M., F. Bray, et al. Estimating the world cancer burden: Globocan 2000. Int J Cancer, v.94, n.2, Oct 15, p.153-6. 2001.

Phillips, D. H. Smoking-related DNA and protein adducts in human tissues. Carcinogenesis, v.23, n.12, Dec, p.1979-2004. 2002.

Piantelli, M., S. Iacobelli, et al. Lack of expression of galectin-3 is associated with a poor outcome in node-negative patients with laryngeal squamous-cell carcinoma. J Clin Oncol, v.20, n.18, Sep 15, p.3850-6. 2002.

Pintos, J., E. L. Franco, et al. Human papillomavirus and prognoses of patients with cancers of the upper aerodigestive tract. Cancer, v.85, n.9, May 1, p.1903-9. 1999.

Plas, D. R. e C. B. Thompson. Cell metabolism in the regulation of programmed cell death. Trends Endocrinol Metab, v.13, n.2, Mar, p.75-8. 2002.

Puglisi, F., A. M. Minisini, et al. Galectin-3 expression in non-small cell lung carcinoma. Cancer Lett, v.212, n.2, Aug 30, p.233-9. 2004.

Ragin, C. C., F. Modugno, et al. The epidemiology and risk factors of head and neck cancer: a focus on human papillomavirus. J Dent Res, v.86, n.2, Feb, p.104-14. 2007.

Redondo, M., F. Esteban, et al. Expression of the antiapoptotic proteins clusterin and bcl-2 in laryngeal squamous cell carcinomas. Tumour Biol, v.27, n.4, p.195-200. 2006.

Rosenthal, D. S., R. Ding, et al. Intact cell evidence for the early synthesis, and subsequent late apopain-mediated suppression, of poly(ADP-ribose) during apoptosis. Exp Cell Res, v.232, n.2, May 1, p.313-21. 1997.

Ruf, A., J. Mennissier De Murcia, et al. Structure of the catalytic fragment of poly(AD-ribose) polymerase from chicken. Proc Natl Acad Sci U S A, v.93, n.15, Jul 23, p.7481-5. 1996.

Sanguinetti, C. J., E. Dias Neto, et al. Rapid silver staining and recovery of PCR products separated on polyacrylamide gels. Biotechniques, v.17, n.5, Nov, p.914-21. 1994.

Sanjuan, X., P. L. Fernandez, et al. Differential expression of galectin 3 and galectin 1 in colorectal cancer progression. Gastroenterology, v.113, n.6, Dec, p.1906-15. 1997. 
Saussez, S., I. Camby, et al. Galectins as modulators of tumor progression in head and neck squamous cell carcinomas. Head Neck, v.29, n.9, Sep, p.874-84. 2007.

Scheffner, M., H. Romanczuk, et al. Functions of human papillomavirus proteins. Curr Top Microbiol Immunol, v.186, p.83-99. 1994.

Scheurlen, W., A. Stremlau, et al. Rearranged HPV 16 molecules in an anal and in a laryngeal carcinoma. Int J Cancer, v.38, n.5, Nov 15, p.671-6. 1986.

Schreiber, V., D. Hunting, et al. A dominant-negative mutant of human poly(ADP-ribose) polymerase affects cell recovery, apoptosis, and sister chromatid exchange following DNA damage. Proc Natl Acad Sci U S A, v.92, n.11, May 23, p.4753-7. 1995.

Scully, C., J. K. Field, et al. Genetic aberrations in oral or head and neck squamous cell carcinoma 3: clinico-pathological applications. Oral Oncol, v.36, n.5, Sep, p.404-13. 2000.

Shangina, O., P. Brennan, et al. Occupational exposure and laryngeal and hypopharyngeal cancer risk in central and eastern Europe. Am J Epidemiol, v.164, n.4, Aug 15, p.36775. 2006.

Shimizu, S., F. Nomura, et al. Expression of poly(ADP-ribose) polymerase in human hepatocellular carcinoma and analysis of biopsy specimens obtained under sonographic guidance. Oncol Rep, v.12, n.4, Oct, p.821-5. 2004.

Shimonishi, T., K. Miyazaki, et al. Expression of endogenous galectin-1 and galectin-3 in intrahepatic cholangiocarcinoma. Hum Pathol, v.32, n.3, Mar, p.302-10. 2001.

Shiobara, M., M. Miyazaki, et al. Enhanced polyadenosine diphosphate-ribosylation in cirrhotic liver and carcinoma tissues in patients with hepatocellular carcinoma. $\underline{\mathrm{J}}$ Gastroenterol Hepatol, v.16, n.3, Mar, p.338-44. 2001.

Silva, A. M., C. A. Vilanova-Costa, et al. WITHDRAWN: Human papillomavirus detection and genotyping in squamous cell carcinomas of the larynx. J Virol Methods, Aug 8. 2008.

Smith, S. The world according to PARP. Trends Biochem Sci, v.26, n.3, Mar, p.174-9. 2001.

Soldani, C., M. G. Bottone, et al. Two-color fluorescence detection of Poly (ADP-Ribose) Polymerase-1 (PARP-1) cleavage and DNA strand breaks in etoposide-induced apoptotic cells. Eur J Histochem, v.45, n.4, p.389-92. 2001.

Song, Y. K., T. R. Billiar, et al. Role of galectin-3 in breast cancer metastasis: involvement of nitric oxide. Am J Pathol, v.160, n.3, Mar, p.1069-75. 2002. 
Sousa, R., N. Dostatni, et al. Control of papillomavirus gene expression. Biochim Biophys Acta, v.1032, n.1, Jun 1, p.19-37. 1990.

St John, M. A., E. Abemayor, et al. Recent new approaches to the treatment of head and neck cancer. Anticancer Drugs, v.17, n.4, Apr, p.365-75. 2006.

Staibano, S., S. Pepe, et al. Poly(adenosine diphosphate-ribose) polymerase 1 expression in malignant melanomas from photoexposed areas of the head and neck region. Hum Pathol, v.36, n.7, Jul, p.724-31. 2005.

Syrjanen, K. J. e S. M. Surjanen. Histological evidence for the presence of condylomatous epithelial lesions in association with laryngeal squamous cell carcinoma. ORL J Otorhinolaryngol Relat Spec, v.43, n.4, p.181-94. 1981.

Syrjanen, K. J. e S. M. Syrjanen. Human papillomavirus DNA in bronchial squamous cell carcinomas. Lancet, v.1, n.8525, Jan 17, p.168-9. 1987.

Human papillomavirus (HPV) typing as an adjunct to cervical cancer screening. Cytopathology, v.10, n.1, Feb, p.8-15. 1999.

Syrjanen, S. Human papillomavirus (HPV) in head and neck cancer. J Clin Virol, v.32 Suppl 1, Mar, p.S59-66. 2005.

Syrjanen, S. e M. Puranen. Human papillomavirus infections in children: the potential role of maternal transmission. Crit Rev Oral Biol Med, v.11, n.2, p.259-74. 2000.

Szyfter, K., K. Hemminki, et al. Tobacco smoke-associated N7-alkylguanine in DNA of larynx tissue and leucocytes. Carcinogenesis, v.17, n.3, Mar, p.501-6. 1996.

Teni, T., S. Pawar, et al. Expression of bcl-2 and bax in chewing tobacco-induced oral cancers and oral lesions from India. Pathol Oncol Res, v.8, n.2, p.109-14. 2002.

Tommasino, M., R. Accardi, et al. The role of TP53 in Cervical carcinogenesis. Hum Mutat, v.21, n.3, Mar, p.307-12. 2003.

Trask, D. K., G. T. Wolf, et al. Expression of Bcl-2 family proteins in advanced laryngeal squamous cell carcinoma: correlation with response to chemotherapy and organ preservation. Laryngoscope, v.112, n.4, Apr, p.638-44. 2002.

Tuyns, A. J., J. Esteve, et al. Cancer of the larynx/hypopharynx, tobacco and alcohol: IARC international case-control study in Turin and Varese (Italy), Zaragoza and Navarra (Spain), Geneva (Switzerland) and Calvados (France). Int J Cancer, v.41, n.4, Apr 15, p.483-91. 1988. 
Venuti, A., V. Manni, et al. Physical state and expression of human papillomavirus in laryngeal carcinoma and surrounding normal mucosa. J Med Virol, v.60, n.4, Apr, p.396-402. 2000.

Vousden, K. Interactions of human papillomavirus transforming proteins with the products of tumor suppressor genes. Faseb J, v.7, n.10, Jul, p.872-9. 1993.

Walboomers, J. M., M. V. Jacobs, et al. Human papillomavirus is a necessary cause of invasive cervical cancer worldwide [see comments]. J Pathol, v.189, n.1, p.12-9. 1999.

Wang, J. L., R. M. Gray, et al. Nucleocytoplasmic lectins. Biochim Biophys Acta, v.1673, n.12, Jul 6, p.75-93. 2004.

Watts, S. L., E. E. Brewer, et al. Human papillomavirus DNA types in squamous cell carcinomas of the head and neck. Oral Surg Oral Med Oral Pathol, v.71, n.6, Jun, p.7017. 1991.

Whisler, L. C., N. B. Wood, et al. Regulators of proliferation and apoptosis in carcinoma of the larynx. Laryngoscope, v.108, n.5, May, p.630-8. 1998.

Wilson, V. G., M. West, et al. Papillomavirus E1 proteins: form, function, and features. Virus Genes, v.24, n.3, Jun, p.275-90. 2002.

Wsierska-Gadek, J. e M. Horky. How the nucleolar sequestration of p53 protein or its interplayers contributes to its (re)-activation. Ann N Y Acad Sci, v.1010, Dec, p.266-72. 2003.

Xavier, S. D., I. Bussoloti Filho, et al. Prevalence of histological findings of human papillomavirus (HPV) in oral and oropharyngeal squamous cell carcinoma biopsies: preliminary study. Braz J Otorhinolaryngol, v.71, n.4, Jul-Aug, p.510-4. 2005.

Xie, X., O. P. Clausen, et al. The prognostic value of spontaneous apoptosis, Bax, Bcl-2, and p53 in oral squamous cell carcinoma of the tongue. Cancer, v.86, n.6, Sep 15, p.913-20. 1999.

Yang, R. Y., G. A. Rabinovich, et al. Galectins: structure, function and therapeutic potential. Expert Rev Mol Med, v.10, p.e17. 2008.

Yu, S. W., H. Wang, et al. Mediation of poly(ADP-ribose) polymerase-1-dependent cell death by apoptosis-inducing factor. Science, v.297, n.5579, Jul 12, p.259-63. 2002.

Yuen, A. P., K. Y. Lam, et al. The clinicopathological significance of bcl-2 expression in the surgical treatment of laryngeal carcinoma. Clin Otolaryngol Allied Sci, v.26, n.2, Apr, p.129-33. 2001. 
Zatonski, W., H. Becher, et al. Tobacco, alcohol, and diet in the etiology of laryngeal cancer: a population-based case-control study. Cancer Causes Control, v.2, n.1, Jan, p.3-10. 1991.

Zhang, W., H. Y. Shi, et al. Maspin overexpression modulates tumor cell apoptosis through the regulation of Bcl-2 family proteins. BMC Cancer, v.5, p.50. 2005.

Zheng, Z. M. e C. C. Baker. Papillomavirus genome structure, expression, and posttranscriptional regulation. Front Biosci, v.11, p.2286-302. 2006.

Zur Hausen, H. Papillomavirus infections--a major cause of human cancers. Biochim Biophys Acta, v.1288, n.2, Oct 9, p.F55-78. 1996.

Papillomaviruses and cancer: from basic studies to clinical application. Nat Rev Cancer, v.2, n.5, May, p.342-50. 2002.

Zvrko, E., Z. Gledovic, et al. Risk factors for laryngeal cancer in Montenegro. Arh Hig Rada Toksikol, v.59, n.1, Mar, p.11-8. 2008. 


\section{Anexo 1}

\begin{tabular}{cc|c|}
\hline HOSPITAL DAS CLINICASTDA FACULDADE DE MEDICINA \\
DE RIBEIRÃO PRETO DA UNIVERSIDADE DE SÃO PAULO \\
Comites de Ética em Pesquisa.
\end{tabular}

Ribeirâo Preto, 07 de junho de 2006

Oficio $n^{\circ} 1560 / 2006$

$\mathrm{CEP} / \mathrm{SPC}$

Prezada Senhora:

O trabalho intitulado "AVALIAÇĀo DA PROGRESSÃO TUMORAL DO CÂNCER DE LARINGE ASSOCIADA À INFECÇÃO PELO PAPILOMAVIRUS HMANO (HPV)", foi analisado pelo Comitê de Ética em Pesquisa, em sua $226^{a}$ Reuniâo Ordinária realizada em 05/06/2006, e enquadrado na categoria: APROVADO, de acordo com o Processo HCRP n ${ }^{\circ} 5508 / 2006$.

Aproveito a oportunidade para apresentar a Vossa Senhoria protestos de estima e consideraçăo.

PROF. DR. SÉRGIO PEREIRA DA CUMHA

Coordenador do Comitê de Ética em Pesquisa do HCRP e da FMRP-USP

Ilustrissima Senhora

FABIANA ALVES DE MIRANDA

PROF. DR. EDSON GARCIA SOARES (Orientador)

Depto. de Patologia

Em măos 


\section{ARTIGo}




\section{GALECTIN-3 OVEREXPRESSION IN INVASIVE LARYNGEAL CARCINOMA, ASSESSED BY COMPUTER-ASSISTED ANALYSIS}

Fabiana A. Miranda ${ }^{1 *}$, Marcela K. Hassumi ${ }^{1}$, Marcia C. M. Guimarães ${ }^{1}$, Renata T. Simões $^{3}$, Tarsia G.A. Silva ${ }^{2}$, Régia C. P. Lira ${ }^{1}$, Ana M. Rocha ${ }^{1}$, Celso T MendesJunior $^{4}$, Eduardo A Donadi ${ }^{3}$, Christiane P. Soares ${ }^{2}$, and Edson G. Soares ${ }^{1}$

${ }^{1}$ Department of Pathology, Faculty of Medicine of Ribeirão Preto, University of São

Paulo-USP, SP, Brazil

${ }^{2}$ Department of Clinical Analysis, School of Pharmaceutical Sciences, UNESP, SP, Brazil.

${ }^{3}$ Division of Clinical Immunology, Department of Medicine, Faculty of Medicine of Ribeirão Preto, University of São Paulo, SP, Brazil

${ }^{4}$ Departament of Chemistry, Faculty of Philosophy, Science and Letters of Ribeirão Preto, University of São Paulo, 14040-901, Ribeirão Preto-SP, Brazil

\section{Address for correspondence:}

Fabiana Alves Miranda

Department of Pathology

Faculty of Medicine of Ribeirão Preto, University of São Paulo

Avenida dos Bandeirantes, 3900,

14049-900, Ribeirão Preto, SP, Brazil.

Phone: +55 1636023179

E-mail: famiranda@usp.br 


\section{SUMMARY}

The larynx is the most common site of malignancy in the upper aerodigestive tract. In Brazil, malignant laryngeal lesions represent $2 \%$ of all cancers, with about 3,000 annual deaths. The association between human papillomavirus (HPV) and laryngeal cancer is still contradictory. The aim of the present retrospective study was to determine the expression of galectin-3 immunoperoxidase in laryngeal carcinoma byexamining paraffine-embedded larynx biopsies from 65 patients, 10 in situ laryngeal carcinomas, 27 laryngeal carcinomas without metastases, and 28 with metastases. Twenty-eight cervical lymph nodes from patients with metastatic lesions were also evaluated. Nested PCR was performed in order to detect and type HPV DNA. Galectin 3 expression was assessed by immunohistochemistry using a computer-assisted system. Among 65 patients, 55 (84.6) were positive to beta-globin (internal control) and $10(15.4 \%)$ patients were beta-globin negative and they were excluded to the HPV evaluation. Thus, 7 (12.7\%) out of 55 patients were HPV positive and 48 (87.3\%) out of 55 patients were HPV negative. High expression of galectin 3 was observed in invasive laryngeal tumors, suggesting that galectin 3 could be associated with the invasiveness and agressiveness of laryngeal carcinomas.

Key Words: Galectin-3, HPV, laryngeal carcinoma, immunohistochemistry, PCR 


\section{Introduction}

Head and neck squamous cell carcinomas (HNSCCs) are the sixth most common form of cancer worldwide, with a total of 640,000 new cases a year. The larynx is part of the head and neck, with a total of 159,000 new cases of carcinoma per year, more commonly affecting males (Almodori et al, 2004; Hunter et al, 2005; Koakinem et al, 2007). In Brazil, laryngeal tumors represent about $2.0 \%$ of all cancers, corresponding to approximately 8,000 new cases annually (Wünsch, 2004).

Alcohol and tobacco are the two best recognized risk factors for cancer of the larynx and human papillomavirus (HPV) has been described as a cofactor for laryngeal carcinogenesis. However, the relative frequency of HPV genotypes in carcinoma of the larynx is still unknown, with several studies demonstrating variable frequencies ranging from 8 to $58.8 \%$ (Almadori et al., 2001; García-Milían et al., 1998; Atula et al., 1999; Venuti et al., 2000; Jacob et al., 2002).

Novel approaches are thus required to provide head and neck oncologists with more effective armamentarium against these challenging diseases. Ideally, reliable identification of high-risk patients will enable tailored therapeutic regimens and hopefully improve the predicted unfavurable prognosis for this subgroup (Plzák et al., 2004). Minimal residual disease and early recurrences and metastases should be detected using molecular markers (Almadori et al., 2005). Galectin-3 has been proposed as a biological marker of agressiveness in several types of head and neck tumors (Saussez et al., 2007). Galectin-3 expression in head and neck tumors is controversial. Whereas 
previous studies have demonstrated a reduced expression of galectin-3 in parathyroid carcinomas, galectin expression was found to be high in primary and metastatic tumors (Bergero et al., 2005). It has been recently reported that epigenetic changes of galectin DNA are responsible for differential expression in cancers (Ahmed et al., 2007). Therefore, galectin-3 has been considered to be a prognostic factor in different tumors, such as colorectal cancer, head and neck cancer, pancreatic cancer and gastric cancer (Puglisi et al, 2004) .

In view of the above considerations, the aim of the present study was to determine the expression of the galectin-3 immunoperoxidase in in situ laryngeal carcinomas and in invasive carcinomas with and without metastases in cervical lymph nodes. An additional objective was to compare quantitative analyses of galectin-3 by a computer-assisted system to quantitation by a pathologist.

\section{Material and Methods}

\section{Specimens}

Between 1995 and 2004, 65 laryngeal cell carcinomas were selected from the archives of the Pathology Department, School of Medicine of Ribeirão Preto, University of São Paulo (USP), Brazil. The study protocol was approved by the Brazilian Institutional Ethics Committee on Human Experimentation. The 65 malignant laryngeal neoplasias were stratified into three subgroups: 10 in situ carcinoma $\left(\mathrm{LSCC}^{\mathrm{S}}\right), 27$ invasive carcinomas without metastases $\left(\mathrm{LSCC}^{\mathrm{WT}}\right)$, and 28 invasive carcinomas with cervical lymph node metastases $\left(\mathrm{LSCC}^{\mathrm{W}}\right)$. In addition, 28 cervical lymph nodes (LB) from the patients with $\mathrm{LSCC}^{\mathrm{W}}$ were also evaluated. Thin $5 \mu \mathrm{m}$ sections were cut, placed 
on organosilane-pretreated slides and submitted to immunohistochemical assays (galectin-3). Additionally, $10 \mu \mathrm{m}$ section was cut for DNA extraction and HPV typing. Clinicopathological information about the patients such as age, sex, history of smoking, and history of alcohol consumption was obtained from the patients' medical recorsds.

\section{Immunohistochemistry for galectin-3}

Immunohistochemistry was performed for the detection of galectin-3 protein using the avidin-biotin peroxidase complex (ABC) method (Novoscastra, Newcastleupon-Tyne, United Kingdom). Paraffin-embeded sections $(5 \mu \mathrm{m})$ were deparaffnized in xylene and then rehydrated through a graded alcohol series. For antigen retrieval, the sections were immersed in $10 \mathrm{mM}$ sodium citrate $\left(\mathrm{C}_{6} \mathrm{H}_{5} \mathrm{Na}_{3} \mathrm{O}_{7}\right)$ buffer, $\mathrm{pH}$ 6.0, and submitted to steam heating for 40 minutes at $95{ }^{\circ} \mathrm{C}$. The sections were cooled at room temperature and immersed in one change of hydrogen peroxide in PBS (3\%) for $20 \mathrm{~min}$. The sections were rinsed in three consecutive $1 \mathrm{M}$ standard phospate-saline buffered (PBS) baths and incubated with horse serum for 30 minutes for nonspecific blockage The sections were incubated with a primary monoclonal antibody raised against galectin-3 (clone 9c4 diluted 1:100, Novocastra). The slides were placed in a humidified chamber at room temperature overnight. After incubation with primary antibodies, the slides were rinsed in 3 changes of PBS and immunoperoxidase staining was performed using a biotinylated secondary antibody and the streptavidin-peroxidase complex (Novocastra). In both steps, the sections were incubated for 30 minutes at room temperature according to manufacturer instructions. Between the stages of the above 
procedure, the sections were carefully rinsed with 3 changes of PBS. Subsequently, the sections were incubated in a solution containing $5 \mathrm{mg}$ of diaminobenzidine (GIBBICO, Gaithersburg, Maryland, USA) dissolved in $5 \mathrm{ml}$ of PBS, and $100 \mu \mathrm{L}$ of fresh of peroxidase solution ( $450 \mu \mathrm{L}$ of PBS and $50 \mu \mathrm{L}$ of hydrogen peroxide). The DAB reaction was blocked with one change of PBS, followed by rinses in distilled water. Next, the sections were counterstained with Harris' hematoxylin for 1 minute, following several rinses with distilled water. The sections were dehydrated with three absolute alcohol changes, followed by two immersion changes in xylol and mounted on Permount mounting medium (MERCK, Darmstadt, Germany).

\section{Controls}

Three controls were included for each section and for all proteins evaluated: positive, negative and normal laryngeal tissue. The positive control was a section of human lymphoma (galectin3). The negative control was the same human tissue used as positive control, in which the primary antibody was omitted from the assay and replaced with PBS. The normal laryngeal control was performed in order to obtain the basal levels of galectin-3 and the cut-off value by which the quantitiative galectin-3 expression in laryngeal carcinomas was determined. 


\section{Image acquisition and galectin-3 image analysis quantification (IM)}

Positive cytoplasms were automatically quantified by a computer-assisted system (Image-Pro Plus - Cybernetics, MD, USA) consisting of a microscope, a digital camera and a software package. A mean of ten random microscope fields were selected in order to analyze 1000 cytoplasm fields per biopsy in all patient sections. The image acquisition of the sections of 65 patients stratified into in situ laryngeal carcinoma, laryngeal invasive squamous cell carcinoma (with and without metastasis) and cervical lymph node biopsies was performed on an electron photomicrograph and the image was then processed and analyzed by the software. For each slide, the digitized image segmentation was controlled interactively by the RGB color filter existing in the software program. The automatic cytoplasm count was determined and expressed as percentage.

Qualitative immunolabeling evaluation

All scoring and qualitative interpretation of immunohistochemical results was carried out by an experienced pathologist and classified as negative, discrete, moderate or intense immunolabeling. In the present study, we considered the expression of galectin-3 to be low when laryngeal biopsies were not immunolabeled or showed discrete immunostaining. Galectin-3 expression was classified as high when the pathologist observed moderate or intense immunolabeling.

$H P V$ detection and typing 
Genomic DNA was obtained from 2 sections of paraffin blocks (10 $\mu \mathrm{m}$ each), according to the protocol proposed by (Bettini et al., 2003), modified, and amplified by PCR using the GP5+ and GP6+ primers (Manos et al., 1989), which amplify a $150 \mathrm{bp}$ DNA fragment and which were used for generic HPV amplification. Amplification was performed together with a set of primers for a beta globin (PCO3 and PCO4) gene ((PCO3+ CTT CTG ACA CAA CTG TGT TCA CTA GC and PCO4+ TCA CCA CAA CTT CAT CCA CGT TCA CC) as an internal control of amplification. The generic HPV-positive samples was amplified with specific primers for HPV16, HPV18, HPV31, HPV33, HPV6 and HPV11 as described by Walboomers et al. (1999) The amplification procedure for HPV detection and typing was carried out using a final volume of $25 \mu$. The reaction mixture included $20 \mathrm{ng}$ of genomic DNA, $0.20 \mathrm{mM}$ deoxynucleoside triphosphate (Pharmacia, Uppsala, Sweden), $0.6 \mu \mathrm{M}$ of each primer (IDT, IA, USA), 1.25 U Taq polymerase (Invitrogen, Brazil), $3 \mathrm{mM} \mathrm{MgCl}$, and 1x buffer (Invitrogen, Brazil). The cycling conditions for almost all generic and HPV types consisted of an initial denaturation step at $94^{\circ} \mathrm{C}$ for $5 \mathrm{~min}$, followed by 35 cycles at $94^{\circ} \mathrm{C}$ for $1 \mathrm{~min}$, at $55^{\circ} \mathrm{C}$ for $1 \mathrm{~min}$, and at $72^{\circ} \mathrm{C}$ for $1 \mathrm{~min}$, with a final extension cycle of $72^{\circ} \mathrm{C}$ for $10 \mathrm{~min}$. An annealing temperature of $60^{\circ} \mathrm{C}$ was used for HPV11 amplification. PCR products were separated on $10 \%$ nondenaturing polyacrylamide gels followed by a silver staining procedure, as described by Sanguinetti et al. (1994).

\section{HPV Controls}


The HPV positive control and beta-globin control were cervical samples collected by cytologic cytobrushing. As a negative control, all PCR reagents were added to an Eppendorf tube containing no DNA sample. For HPV6 and HPV 11 typing, the PCR controls were HP-positive DNA collected from cervical samples. For HPV16 and HPV18 controls, DNA was extracted fromSiHa and HeLa cell lines, respectively, whereas HPV31 and HPV 33 were from patient samples. All controls (HPV16, 18, 31 and 33) were kindly provided by Dr Luisa Lina Villa, Ludwig Institute for Cancer Research, Sao Paulo, Brazil.

\section{Statistical Analysis}

The distributions of three clinical parameters (gender, tobacco and alcohol exposure) were compared between the different subgroups of laryngeal malignant neoplasias $\left(\mathrm{LSCC}^{\mathrm{S}}, \mathrm{LSCC}^{\mathrm{WT}}\right.$ and $\mathrm{LSCC}^{\mathrm{W}}$ ) by means of the two-sided Fisher's exact test for $2 \times 2$ contingency tables, with the aid of the GraphPad InStat software (San Diego, CA, USA), which was also used to estimate the odds ratio (OR) and its $95 \%$ confidence interval (95\% C.I.). Age, reported as arithmetic mean and standard deviation, was also compared between groups by means of the two-sided Student unpaired $t$-test.

Qualitative differences in galectin 3 expression between groups determined according to clinical parameters were evaluated by means of the Fishers exact test (in case of $2 \times 2$ tables) using the GraphPad InStat software or an exact test that uses the Metropolis algorithm to obtain an unbiased estimate of the exact $\mathrm{P}$ value and its standard 
error (in case of more complex $\mathrm{RxC}$ tables) using the $\mathrm{RXC}$ software (http://www.marksgeneticsoftware.net/rxc.htm).

The standard survival time analysis was performed using the Kaplan-Meier curves, and differences between curves were evaluated by the Gehan's Wilcoxon test, using the Statistica 8.0 software (StatSoft, Tulsa, USA). Overall survival was computed from the date of surgery to documented date of the follow-up or death, whereas diseasefree survival was considered to cover the period from the date of surgery to the date of recurrence.

For quantitative analysis, since the galectin-3 expression data did not meet the normality assumption for parametric tests, non parametric analyses were conducted. The Kruskal-Wallis non-parametric test followed by Dunn's multiple comparison post-test was applied to compare the mean expression levels of galectin-3 among the three subgroups of laryngeal malignant neoplasias $\left(\mathrm{LSCC}^{\mathrm{S}}, \mathrm{LSCC}^{\mathrm{WT}}\right.$ and $\left.\mathrm{LSCC}^{\mathrm{W}}\right)$. The mean expression levels of galectin-3 between the invasive carcinomas with metastasis biopsies $\left(\mathrm{LSCC}^{\mathrm{W}}\right)$ and cervical lymph nodes biopsies (LB) rising from such laryngeal metastatic lesions were compared using the Wilcoxon matched-pairs signed-ranks test. The correlation analysis between $\mathrm{LSCC}^{\mathrm{W}}$ and LB was calculated using the Spearman rank correlation test. P-values were two-sided and the level of significance was set at 5\%( $\alpha=$ $0.05)$.

As mentioned above, the intensity of staining pattern of galectin-3 in each sample was classified as low and high immunostaining intensity. To compare the distribution of these two types of intensity among the different subgroups of laryngeal malignant neoplasias (in situ carcinoma, invasive carcinomas without metastasis and 
invasive carcinomas with metastasis), the nonparametric two-sided Fisher's exact test for 2 x 2 contingency tables was employed. All data were analyzed using the GraphPad Instat software (San Diego, CA, USA).

\section{Results}

Laryngeal carcinomas and clinical parameters

The clinical parameters of the patients with in situ laryngeal carcinoma and invasive laryngeal carcinoma without metastasis and with metastasis demonstrated no significant association with age, sex or tobacco consumption (Table 1). However, the patients were predominantly males exposed to tobacco and alcohol.

\section{Galectin-3 and clinicopathologic Features}

The relationship between galectin-3 expression and clinicopathologic features (as histological grade, TNM stage and recurrence) doesn't showed any statistical difference between the qualitative expression of galectin-3 and the laryngeal carcinomas studied (Kaplan-Meier curve for cumulative disease-free rate of patients with laryngeal carcinomas). On the contrary, galectin-3 expression was positively associated with tumor site $(p=0.0003 \pm 0.001)$ when analyzed in $\mathrm{LSCC}^{\mathrm{WT}}$, summarized in Table 2. We haven't found statistical significance in the results of survival disease-free $(p=0.5284)$, as summarizes Figure 1. There was no significant difference between the galectin-3 low 
expression and the galectin-3 high-expression in all groups of laryngeal carcinomas $\left(\mathrm{LSCC}^{\mathrm{S}}, \mathrm{LSCC}^{\mathrm{WT}}\right.$ and $\left.\mathrm{LSCC}^{\mathrm{W}}\right)$ studied.

Human Papillomavirus detection, typing and correlation with expression of galectin-3

Among 65 patients, 55 (84.6) were positive to beta-globin (internal control) and $10(15.4 \%)$ patients were beta-globin negative, indicating that the DNA from paraffin sections was degradated. Therefore, they were excluded to the HPV evaluation. Thus, in the present study, 7(12.7\%) out of 55 patients were HPV positive and HPV-DNA of low risk types was observed in $1(14.3 \%)$, whereas high-risk types were detected in 6 (85.7\%). Forty-eight $(87.3 \%)$ out of 55 patients were HPV negative (Table 3). Qualitatively, 5 out of $7 \mathrm{HPV}+$ patients (71.4\%) presented high expression levels of Galectin 3, while only 37 out of 55 HPV-patients (67.2\%) presented high expression levels of Galectin 3; however, such figures are not statistically significant $(\mathrm{p}=0.6079$, Fisher's exact test).The same happened when we analyzed quantitatively the expression of galectin-3 and HPV+/- patients ( $\mathrm{p}=0.5034$, Mann-Whitney Test).

Immunohistochemical expression of galectin-3 in laryngeal carcinomas

In the quantitative evaluation of galectin-3 (Table 4, Figure $2 \mathrm{D}$ and E), we observed a significantly higher expression in invasive laryngeal carcinoma, independent of the presence or absence of metastases or in their lymph nodes $\left(\mathrm{LSCC}^{\mathrm{WT}}, \mathrm{LSCC}^{\mathrm{W}}\right.$ and LB), when compared with in situ laryngeal carcinoma (LSCC ${ }^{\mathrm{S}}$ ). Normal laryngeal 
biopsies (Figure $2 \mathrm{C}$ ) and negative controls (Figure 2 B) did not present any immunolabeling in squamous cells and in cylindric cells (Figure $2 \mathrm{C}$ ), whereas the positive control (lymphome non-Hodking) showed specific immunostaining (Figure 2 A). In this study we observed only immunolabeling of galectin-3 in the cytoplasm of tumor cells.

Interestingly, the qualitative evaluation performed by an experienced pathologist also demonstrated a significantly higher intensity of galectin-3 cytoplasmatic expression in invasive carcinomas ( $\mathrm{LSCC}^{\mathrm{WT}}, \mathrm{LSCC}^{\mathrm{W}}$ and $\mathrm{LB}$ ) and a low intensity in $\mathrm{LSCC}^{\mathrm{S}}$ (Table 5, Figure $2 \mathrm{D}$ and $\mathrm{E}$ ). Thus, both quantitative and qualitative galectin-3 expression demonstrated that this protein could be considered a biological marker for invasive laryngeal carcinoma, although it is not related to metastasis.

\section{Discussion}

Among the 65 patients with laryngeal carcinoma we detected a close association between alcohol and tobacco exposure, although no differences were found between in situ and invasive laryngeal lesions. Epidemiological studies have consistently shown that the alcohol drinking and tobacco smoking increase the risk of laryngeal cancer (Altieri et al., 2001). It is a well-accepted fact that heavy drinkers tend to be heavy smokers. In the present study, the patients were predominatly Caucasian males with a mean age of 59 years. There is ample evidence suggesting that susceptibility to the effects of both alcohol and tobacco is likely to differ in terms of both gender and race (Zang and Wynder, 2001). A case-control study on laryngeal cancer in Sao Paulo, Brazil found an adjusted odds ratio of 7.5 for heavy smokers and of 3.7 for heavy drinkers 
(Sartor, 2003). The population of the present study was from the interior of the state of Sao Paulo and, although we did not determine the number of cigarettes smoked or the amount of alcohol consumed, we detected an odds ratio of 8.1 for alcohol exposure in patients with invasive laryngeal carcinoma. In addition, the odds ratio for tobacco exposure (2.0 for invasive laryngeal carcinoma) was also quite similar to that observed in the previous study (Sartor, 2003).

The larynx is part of the head and neck, due to its various clinical and molecular particularities it has been classified separately from the oral cavity and pharynx (Jemal et al, 2004). In addition, molecular markers could be expressed differentially in the larynx when compared to other head and neck sites. Previous studies have demonstrated a close association between a high expression of galectin-3 and the agressiveness of head and neck tumors (Guillenwater et al., 1996, Saussez et al., 2007, Saussez et al., 2008). The results obtained from analysis of clinicopathological data (as tumor site, histological grade, TNM stage, survival and recurrence) of 65 patients with laryngeal carcinoma did't show any relationship with expression of galectin-3, probably because the number of the cases studied was too small. Some authors in their studies also didn't find relationship with some of clinicopathological data like tumor site, TNM stage, but they found some relationship when the correlation was between expression of galectin-3 was and survival, recurrence, histological grade and tumor keratinization ( Piantelli et al., 2002, Plazak et al., 2004, Saussez et al., 2006).

While the relationship between anogenital cancer and HPV has been clearly demonstrated, the role of HPV in laryngeal carcinomas is unclear and contradictory results have been reported thus far (Jacob et al., 2002; Morshed et al., 2004., Lindeberg, 
1999). Our findings demonstrated that only seven of 55 patients were HPV positive. This result supports the view that the role of HPV is more important in head and neck tumors than in the larynx (Koskine et al., 2007). The reported range of HPV frequency in these tumors is 8 to $58.8 \%$ and the reason for this incredible range could be only be explained by false-positive results in many of these reports (Lindeberg and Krogdahl, 1999). Although different sample types (fresh-frozen, paraffin-embedded) may influence the result, convincing data exist as to a low prevalence of HPV in laryngeal carcinomas (Koskine et al., 2007, Lindeberg and Krogdahl, 1999). Nevertheless, tumors from HPVinfected patients were high risk types $(n=4)$ and although their frequency was low, a close association was observed with those types and with invasive laryngeal carcinoma.

Galectin-3 is a multifunctional effector and the only chimera-type member of the galectin family of endogenous lectins, which share specificity with beta-galactosides and have a jelly-roll-like folding pattern (Wang et al., 2004). This protein acts in the modulation of cell-cell, cell-extracellular matrix interactions and in the regulation of proliferation and apoptosis/anoikis. Thus, galectin-3, is involved in various biological phenomena, including cell growth, adhesion, differentiation, angiogenesis, and apoptosis (Saussez et al 2007). Galectin-3 exerts different functions in a variety of neoplastic cell types, playing a role in tumorigenesis and metastasis (Puglisi et al, 2004) modifying the levels of migration of cancer cells (Saussez et al 2007) .However, to our knowledge, the present study was the first to assess both the quantitative and qualitative expression of galectin-3 in and in invasive laryngeal carcinomas. High intensity and number of cells expressing galectin-3 were found, indicating a close relationship between overexpression of galectin-3 and invasive laryngeal cancer. Galectin-3 expression seems 
to be positively associated with tumor keratinization and histological grade and a significant correlation was found between tumor galectin-3 positivity and a longer metastasis-free and overall survival of patients with laryngeal carcinoma (Almadori et al., 2005; Piantelli et al. 2002).

Semi-quantitative evaluation and manual cell counts are the procedures commonly used to assess positive labeling of molecular markers in tissue sections. In the present study, no difference was found between the qualitative assessment provided by the pathologist's readings and image analysis of the quantitative immunolabeling of galectin-3. Although the imaging method has several advantages, such as speed of analysis, consistency, and automation (Loukas et al., 2003, Teresa et al., 2007), evaluation by the pathologist is a useful tool guaranteeing a robust immunohistochemical evaluation.

We conclude that galectin-3 was overexpressed in invasive laryngeal carcinoma, representing an important biological marker of larynx cancer agressiveness. Moreover, both quantitative and qualitative determination of galectin-3 expression proved to be a good methodological strategy for the differentiation of in situ from invasive laryngeal cancer

Acknowledgements: The present study was supported by Conselho Nacional de Desenvolvimento Científico e Tecnológico [National Council of Scientific and Technological Development], CNPq, a Brazilian research funding organization. We thank Ana Maria Rocha for the excellent technical assistance 


\section{Literature Cited}

Ahmed H, Banerjee PP, Vasta GR (2007) Differential expression of galectins in normal, benign and malignant prostate epithelial cells: silencing of galectin-3 expression in prostate cancer by its promoter methylation. Biochem Biophys Res Commun 358:241246

Almadori G, Cadoni G, Cattani P, Galli J, Bussu F, Ferrandina G, Scambia G, Fadda, G, Maurizi M (2001) Human papillomavirus infection and epidermal growth factor receptor expression in primary laryngeal squamous cell carcinoma. Clin Cancer Res 7: 3988-93

Alamdori G, Bussu F, Cadoni G, Galli J, Paludetti G, Maurizi M (2005) Molecular markers in laryngeal squamous cell carcinoma: Towards an integrated clinicobiological approach. Eur J Cancer 41:683-93

Altieri A, Garavello W, Bosetti C, Gallus S, La Vecchia C (2005) Alcohol consumption and risk of laryngeal cancer. Oral Oncol 41:956-65

Atula S, Grenman R, Kujari H, Syrjäne S (1999) Detection of Human Papillomavirus (HPV) in laryngeal carcinoma cell lines provides evidence for a heterogeneic cell population. European Journal of Cancer 35: 825-832

Bergero N, De Pompa R, Sacerdote C, Gasparri G, Volante M, Bussolati G, Papotti M (2005) Galectin-3 expression in parathyroid carcinoma: immunohistochemical study of 26 cases. Human Pathology 36: 908-914

Bettini J de S, Soares EG, Duarte G, Simões RT, Simões AL (2003) PCR diagnosis of HPV in cervical biopsies of CIN and invasive neoplasia formely diagnosed as HPV negative. Acta Cytol 47: 545-549

García-Milián R, Hernández H, Panadé L, Rodríguez C, González N, Valenzuela C, Araña MDJ, Perea SE (1998) Detection and typing of Human Papillomavirus DNA in benign and malignant tumours of larymgeal epithelium. Acta Otolaryngol 118: 754-758

Guillenwater A, Xu Xiao-Chun, El-Naggar A K, Clayman G L, Lotan R (1996). Expression of galectins in head and neck squamous cell carcinoma. Head and Neck 18: 422-432

Hunter KD, Parkinson EK, Harrison PR (2005) Profiling early head and neck cancer. Nature Reviews 5:127-135 
Jacob E L, Sreevidya S, Chacko E, Pillai MA (2002). Cellular manifestations of human papillomavirus infection in laryngeal tissues. Journal of Surgical Oncology 79:142-150

Jemal A, Tiwari RC, Murray T, et al (2004) Cancer statistics.Cancer J Clin 54:8-29

Koskinen WJ, Brøndbo K, Mellin Dahlstrand H, Luostarinen T, Hakulinen T, Leivo I, Molijn A, Quint WG, Røysland T, Munck-Wikland E, Mäkitie AA, Pyykkö I, Dillner J, Vaheri A, Aaltonen LM (2007) Alcohol, smoking and human papillomavirus in laryngeal carcinoma: a Nordic prospective multicenter study. J Cancer Res Clin Oncol $133: 673-678$

Lindeberg H, Krogdahl A (1999) Laryngeal cancer and human papillomavirus: HPV is absent in the majority of laryngeal carcinomas. Cancer Letters 146: 9-13

Loukas CG, Wilson GD, Vojnovic B, Linney A (2003) An image analysis-based approach for automated counting of cancer cell nuclei in tissue sections. Cytometry A $55: 30-42$

Morshed K, Polz-Dacewicz, Szymanski M, Polz D (2007) Short-Fragment PCR assay for highly sensitive broad-spectrum detection of human papillomaviruses in laryngeal squamous cell carcinoma and normal mucosa: clinic-pathological evaluation. Eur Arch Otrhinolaryneal 7:569-575

Torrente MC, Ojeda JM (2207) Exploring the relationship between human papillomavirus and larynx cancer. Acta Oto-Laryngologica 127:900-906

Piantelli M, Iacobelli S, Almadori G, Iezzi M, Tinari N, Natoli C, Cadoni G, Lauriola L, Ranelletti FO (2002) Lack of expression of galectin-3 is associated with a poor outcome in node-negative patients with laryngeal squamous-cell carcinoma. J Clin Oncol $18: 3850-3856$

Plzák J, Betka J, Smetana K Jr, Chovanec M, Kaltner H, André S, Kodet R, Gabius HJ (2004) Galectin-3 - an emerging prognostic indicator in advanced head and neck carcinoma. Eur J Cancer 15 : 2324-2330

Puglisi F, Minisini AM, Barbone F, Intersimone D, Aprile G, Puppin C, Damante G, Paron I, Tell G, Piga A, Di Loreto C (2004) Galectin-3 expression in non-small cell lung carcinoma. Cancer Lett $2: 233-239$

Sanguinetti CJ, Dias Neto E, Simpson AJ (1994) Rapid silver staining and recovery of PCR products separated on polyacrylamide gels. Biotechniques 5: 914-921

Sartor SG (2003) Risco Ocupacionais para câncer de laringe: um estudo caso-controle. Thesis São Paulo: Faculdade de Medicina da Universidade de São Paulo 
Saussez S, Camby I, Toubeau G, Kiss R (2006) Galectins as modulators of tumor progression in head and neck squamous cell carcinomas. Wiley InterScience

Saussez S, Decaestecker C, Lorfevre F, Cucu DR, Mortuaire G, Chevalier D, Wacreniez A, Kaltner H, André S, Toubeau G, Camby I, Gabius H-J, Kiss R (2006) High level of galectin-1 expression is a negative prognostic predictor of recurrence in laryngeal squamous cell cacinomas. Int. Journal of Oncology 30: 1109-1117

Saussez S, Lorfevre F, Lequeux T, Laurent G, Chantrain G, Vertongen F, Toubeau G, Decaestecker C, Kiss R (2007) The determination of the levels of circulating galectin-1 and -3 in HNSCC patients could be used to monitor tumor progression and/or responses to therapy. Oral Oncology.

Saussez S, Decaestecker C, Lorfevre F, Chevalier D, Mortuaire G, Kaltner H, Andre S , Toubeau G, Gabius H-J, Leroy X (2008) Increased expression and altered intracellular distribution of adhesion/growth-regulatory lectins galectins-1 and -7 during tumour progression in hypopharyngeal and laryngeal squamous cell carcinomas. Histopathology Mar; 52 (4): 483-93

Teresa DB, Neves KA, Neto CB, Fregonezi PA, de Oliveira MR, Zuanon JA, Donadi EA, Mendes-Junior CT, Soares CP (2007) Computer-assisted analysis of cell proliferation markers in oral lesions. Acta Histochem 5:377-387

Ting Y, Manos M (1990) Detection and typing of genital human papillomaviruses. In: INNIS, M.A.; GELFAND, D.H.; SNINSKY, J.J. (Eds) polymerase chein reaction proteocols: a guide to methods and applications. San Diego: Academic Press 356-367

Venuti A, Manni V, Morello R, De Marco F, Marzetti F, Marcante ML (200) Physical state and expression of human papillomaviruse in laryngeal carcinoma and surrounding normal mucosa. J Med Virol.60:396-402

Walboomers JM, Jacobs MV, Manos MM, Bosch FX, Kummer JA, Shah KV, Snijders PJ, Peto J, Meijer CJ, Munoz N (1999) Human papillomavirus is a necessary cause of invasive cancer worldwide. J. Pathol.189: 12-19

Wang JL, Gray RM, Haudek KC, Patterson RJ (2204) Nucleocytoplasmic lectins. Biochim Biophys Acta 6;1673 (1-2):75-93

Wünsch-Filho V (2004) The epidemiology of laryngeal cancer in Brazil. São Paulo Med. J. 122: 188-194 
Zang EA, Wynder EL (2201) Reevaluation of the confounding effect of cigarette smoking on the relationship between alcohol use and lung cancer risk, with larynx cancer used as a positive control. Prev Med 4:359-370

\section{Figure Legend}

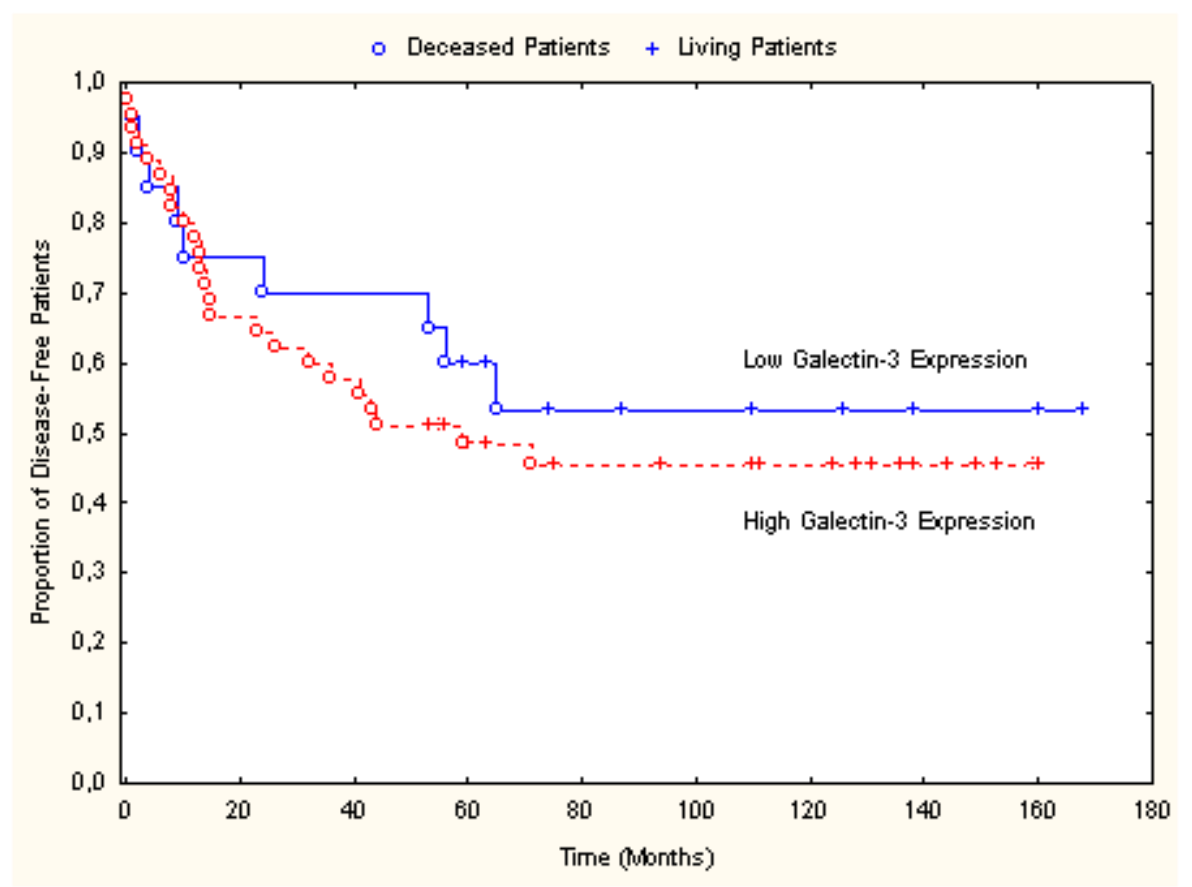

Figure1 Kaplan-Meier curve for cumulative disease-free rate of patients with laryngeal carcinomas. There was no statistical differences between the curves $(p=0.5284)$ 

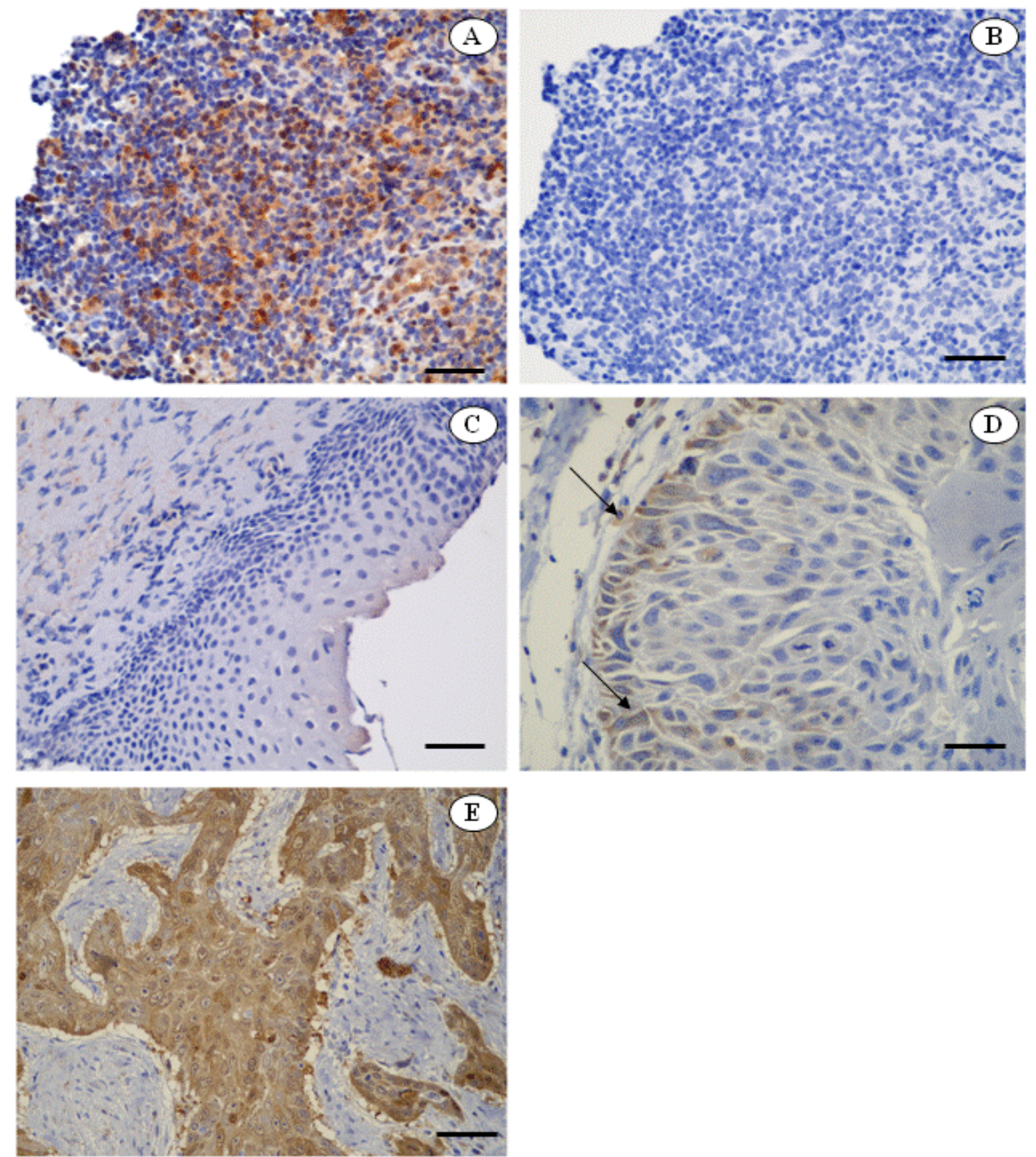

Figure 2 Galectin-3 expression determined by immunoperoxidase staining . (A) Positive control; (B) negative control (non-Hodgkin's lymphoma); (C) Normal larynx negative for galectin-3; (D) low expression of galectin-3 in in situ laryngeal carcinoma, with few immunolabeled cells and weak staining intensity (arrows); (E) high expression of galectin-3 in invasive laryngeal carcinoma without metastases, showing diffuse and high intensity immunolabeling. Bars $=100 \mu \mathrm{m}$ 


\section{Tables}

\section{Table 1}

1 - Clinical parameters of the 65 patients with laryngeal carcinoma stratified according to age, sex and tobacco and alcohol exposure.

\begin{tabular}{|c|c|c|c|c|c|c|c|}
\hline & \multirow{2}{*}{$\begin{array}{c}\text { Age } \\
\mathrm{M} \pm \mathrm{SE}\end{array}$} & \multicolumn{2}{|c|}{ Sex } & \multicolumn{2}{|c|}{ Tobacco exposure } & \multicolumn{2}{|c|}{ Alcohol exposure } \\
\hline & & Male & Female & Yes & No & Yes & No \\
\hline $\operatorname{LSCC}^{\mathrm{S}}(\mathrm{N}=10)$ & $59.2 \pm 2.56$ & 6 & 4 & 6 & 4 & 3 & 7 \\
\hline $\operatorname{LSCC}^{\mathrm{WT}}(\mathrm{n}=27)$ & $59.18 \pm 1.47$ & 18 & 9 & 23 & 3 & 15 & 12 \\
\hline $\operatorname{LSCC}^{\mathrm{W}}(\mathrm{n}=28)$ & $56.07 \pm 1.78$ & 23 & 5 & 28 & 0 & 20 & 8 \\
\hline Comparisons: & $p$-value ${ }^{\mathrm{a}}$ & $\begin{array}{l}p \text {-valu } \\
\text { and } \\
\text { OR va }\end{array}$ & & OR & & or & \\
\hline $\mathrm{LSCC}^{\mathrm{WT}}$ vs. LSCC ${ }^{\mathrm{S}}$ & $\mathrm{p}=0.9945$ & $\begin{array}{l}\mathrm{p}=0.71 \\
\mathrm{OR}=1.3 \\
5.960\end{array}$ & $0.2983-$ & $\begin{array}{l}\mathrm{p}=0.688 \\
\mathrm{OR}=5\end{array}$ & $.9321-$ & $\begin{array}{r}\mathrm{p}=0.26 \\
\mathrm{OR}=2\end{array}$ & 06.182- \\
\hline $\mathrm{LSCC}^{\mathrm{WT}}$ vs. $\mathrm{LSCC}^{\mathrm{W}}$ & $\mathrm{p}=01869$ & $\begin{array}{l}\mathrm{p}=\mathrm{p}= \\
\mathrm{OR}=2.3 \\
8.0722)\end{array}$ & $\begin{array}{l}270 \\
0.6553-\end{array}$ & $\begin{array}{l}p=0.111 \\
O R=8.1 \\
165.650\end{array}$ & 4003- & $\begin{array}{l}\mathrm{p}=0.26 \mathrm{~s} \\
\mathrm{OR}=2 \\
6.1153)\end{array}$ & $.6541-$ \\
\hline
\end{tabular}

a: Unpaired t test; ${ }^{\text {b }}$ : Fisher's exact test.

$\mathrm{LSCC}^{\mathrm{S}}=$ in situ laryngeal carcinoma, $\mathrm{LSCC}^{\mathrm{WT}}=$ invasive laryngeal carcinoma without metastases, $\mathrm{LSCC}^{\mathrm{W}}=$ invasive laryngeal carcinoma with metastases.

$\mathrm{OR}=$ Odds ratio 
Table 2- Quantitative immunoexpression of galectin-3 in laryngeal carcinoma and Clinicopathological data

\begin{tabular}{|c|c|c|c|c|c|c|c|c|c|}
\hline & \multicolumn{2}{|c|}{$\begin{array}{l}\mathrm{LSCC}^{\mathrm{S}} \\
(\mathrm{N}=10)\end{array}$} & \multirow[t]{2}{*}{$p$ value } & \multicolumn{2}{|c|}{$\begin{array}{c}\mathrm{LSCC}^{\mathrm{WT}} \\
(\mathrm{n}=27)\end{array}$} & \multirow[t]{2}{*}{ p value } & \multicolumn{2}{|c|}{$\begin{array}{c}\mathrm{LSCC}^{\mathrm{W}} \\
(\mathrm{n}=28)\end{array}$} & \multirow[t]{2}{*}{$p$ value } \\
\hline & $\mathrm{LE}$ & $\mathrm{HE}$ & & LE & $\mathrm{HE}$ & & $\mathrm{LE}$ & $\mathrm{HE}$ & \\
\hline \multicolumn{10}{|l|}{ Tumor site } \\
\hline Glottic area & 3 & 0 & \multirow{5}{*}{$\begin{array}{c}{ }^{a} p=0.6699 \\
\pm \\
0.0013\end{array}$} & 1 & 5 & \multirow{5}{*}{$\begin{array}{c}{ }^{a} p=0.0003 \\
\pm \\
0.001\end{array}$} & 0 & 9 & \multirow{5}{*}{$\begin{array}{c}{ }^{a} p=0.1669 \\
\pm \\
0.0012\end{array}$} \\
\hline Supraglottic area & 3 & 2 & & 1 & 5 & & 2 & 8 & \\
\hline Subglottic area & 0 & 0 & & 1 & 0 & & 1 & 0 & \\
\hline Larynx* & 1 & 0 & & 0 & 10 & & 1 & 5 & \\
\hline More than two** & 1 & 0 & & 4 & 0 & & 0 & 2 & \\
\hline \multicolumn{10}{|l|}{ Histological grade } \\
\hline Well differentiated & & & \multirow{3}{*}{--} & 1 & 10 & \multirow{3}{*}{$\begin{array}{c}{ }^{a} p=0.2179 \\
\pm \\
0.0010\end{array}$} & 1 & 12 & \multirow{3}{*}{${ }^{b} p=1.0000$} \\
\hline $\begin{array}{l}\text { Moderately } \\
\text { differentiated }\end{array}$ & & & & 3 & 12 & & 1 & 14 & \\
\hline Poorly differentiated & & & & 1 & 0 & & 0 & 0 & \\
\hline \multicolumn{10}{|l|}{ TNM stage } \\
\hline $\mathrm{T} 1-\mathrm{T} 2$ & 2 & 1 & \multirow{2}{*}{${ }^{\mathrm{b}} \mathrm{p}=.3000$} & 2 & 7 & \multirow{2}{*}{${ }^{\mathrm{a}} \mathrm{p}=1.0000$} & 0 & 1 & \multirow{2}{*}{${ }^{\mathrm{b}} \mathrm{p}=1.0000$} \\
\hline T3-T4 & 7 & & & 4 & 14 & & 4 & 23 & \\
\hline No & 0 & 1 & \multirow{2}{*}{${ }^{\mathrm{b}} \mathrm{p}=1.0000$} & 3 & 17 & \multirow{2}{*}{${ }^{\mathrm{a}} \mathrm{p}=0.2896$} & 2 & 4 & \multirow{2}{*}{${ }^{b} \mathrm{p}=01915$} \\
\hline N1-N3 & 1 & 8 & & 3 & 4 & & 2 & 20 & \\
\hline M0 & 6 & 1 & \multirow{2}{*}{${ }^{\mathrm{b}} \mathrm{p}=1.0000$} & 3 & 4 & \multirow{2}{*}{${ }^{\mathrm{a}} \mathrm{p}=0.3278$} & 0 & 0 & \multirow{2}{*}{--} \\
\hline MX & 2 & 1 & & 4 & 16 & & 4 & 24 & \\
\hline \multicolumn{10}{|l|}{ Tumor treatment } \\
\hline Total laryngectomy & 1 & 0 & \multirow{6}{*}{$\begin{array}{c}{ }^{\mathrm{a}} \mathrm{p}=1.0000 \\
\pm \\
0.0000\end{array}$} & 3 & 15 & \multirow{6}{*}{$\begin{array}{c}{ }^{\mathrm{a}} \mathrm{p}=0.7029 \\
\pm \\
0.0014\end{array}$} & 2 & 15 & \multirow{6}{*}{$\begin{array}{c}{ }^{\mathrm{a}} \mathrm{p}=0.2733 \\
\pm \\
0.0012\end{array}$} \\
\hline Partial laryngectomy & 1 & 0 & & 1 & 4 & & 1 & 0 & \\
\hline $\begin{array}{l}\text { Supraglottic } \\
\text { laryngectomy }\end{array}$ & 0 & 0 & & 0 & 2 & & 0 & 1 & \\
\hline $\begin{array}{l}\text { Partial } \\
\text { pharyngolaryngectomy }\end{array}$ & 0 & 0 & & 0 & 0 & & 0 & 0 & \\
\hline $\begin{array}{l}\text { Total } \\
\text { pharyngolaryngectomy }\end{array}$ & 0 & 0 & & 1 & 1 & & 1 & 8 & \\
\hline Others treatments $* * *$ & 6 & 2 & & 0 & 0 & & 0 & 0 & \\
\hline \multicolumn{10}{|l|}{ Recurrence } \\
\hline Local recurrence & 1 & 2 & ${ }^{\mathrm{a}} \mathrm{p}=0.6024$ & 1 & 1 & ${ }^{\mathrm{a}} \mathrm{p}=0.3078$ & 1 & 2 & \\
\hline Distant recurrence & 3 & 1 & \pm & 1 & 4 & \pm & 3 & 2 & $\begin{array}{l}0=0.5000 \pm \\
0.0014\end{array}$ \\
\hline No recurrence & 4 & 2 & 0.0010 & 22 & 2 & 0.0014 & 3 & 20 & \\
\hline
\end{tabular}

LE: Low Expression; HE: High Expression

$\mathrm{LSCC}^{\mathrm{S}}=$ in situ laryngeal carcinoma, LSCC ${ }^{\mathrm{WT}}=$ invasive laryngeal carcinoma without metastases, $\mathrm{LSCC}^{\mathrm{W}}=$ invasive laryngeal carcinoma with metastases; *The whole larynx **Supraglottic and Subglottic; ***Laser $\mathrm{CO} 2$; without surgery 
${ }^{\mathrm{a}} \mathrm{RXC}$ software (http://www.marksgeneticsoftware.net/rxc.htm) $) .{ }^{\mathrm{b}}$ Fisher's Exact Test

Table 3 - HPV DNA detection (GP5+/GP6+) and typing (specific primers) in 55 patients (*) with laryngeal carcinoma stratified according to histological diagnosis.

\begin{tabular}{|c|c|c|c|c|c|c|}
\hline & $\begin{array}{c}\text { HPV } \\
\text { Positive } \\
\text { n (\%) }\end{array}$ & $\begin{array}{c}\text { HPV } \\
\text { Negative } \\
\mathrm{n}(\%) \\
\end{array}$ & $\begin{array}{l}\text { HPV6 } \\
\mathrm{n}(\%) \\
\end{array}$ & $\begin{array}{l}\text { HPV18 } \\
\text { n }(\%)\end{array}$ & $\begin{array}{l}\text { HPV31 } \\
\text { n }(\%)\end{array}$ & $\begin{array}{c}\text { HPV } \\
\text { Two types } \\
\text { n (\%) }\end{array}$ \\
\hline $\mathrm{LSCC}^{\mathrm{S}}$ & $1(14.3)$ & $9(16.4)$ & - & $1(14.3)$ & 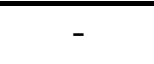 & $1(14.3)^{\mathrm{a}}$ \\
\hline $\mathrm{LSCC}^{\mathrm{WT}}$ & $2(28.6)$ & $25(45.5)$ & $1(14.3)$ & - & - & $1(14.3)^{b}$ \\
\hline $\mathrm{LSCC}^{\mathrm{W}}$ & $2(28.6)$ & $26(47.3)$ & - & - & $1(14.3)$ & $2(28.6)^{c}$ \\
\hline $\begin{array}{l}\text { Lymph } \\
\text { nodes }\end{array}$ & $2(28.6)$ & $26(47.3)$ & - & - & - & \\
\hline Total & $7(10.8)$ & $48(87.3)$ & $1(14.3)$ & $1(14.3)$ & $1(14.3)$ & $4(57.1)$ \\
\hline
\end{tabular}

(*) In 10 (15.4\%) patients, the beta-globin gene were not amplified, indicating DNA degradation, and these patients were not considered to be HPV negative or positive.

Table 4 - Quantitative immunoexpression of galectin-3 in laryngeal carcinoma stratified according to histological diagnosis

\begin{tabular}{|c|c|}
\hline & $\begin{array}{l}\text { Galectin-3 } \\
(\mathrm{M} \pm \mathrm{SEM})\end{array}$ \\
\hline $\operatorname{LSCC}^{\mathrm{S}}(\mathrm{n}=10)$ & $36.0 \pm 10.30$ \\
\hline $\mathrm{LSCC}^{\mathrm{WT}}(\mathrm{n}=27)$ & $70.5 \pm 3.90$ \\
\hline $\operatorname{LSCC}^{\mathrm{W}}(\mathrm{n}=28)$ & $66.3 \pm 5.16$ \\
\hline Lymph nodes $(n=28)$ & $61.5 \pm 4.50$ \\
\hline
\end{tabular}

${ }^{a}$ Analysis of variance (Kruskal Wallis Test): $\mathrm{p}$ values: $\mathrm{LSCC}^{\mathrm{S}}$ versus $\mathrm{LSCC}^{\mathrm{WT}}(\mathrm{p}<0.05) ;$ LSCC $^{\mathrm{S}}$ versus $\operatorname{LSCC}^{\mathrm{W}}(\mathrm{p}<0.05) ;{ }^{\mathrm{c}} \mathrm{LSCC}^{\mathrm{WT}}$ versus $\operatorname{LSCC}^{\mathrm{W}}(\mathrm{p}>0.05)$

Spearman correlation: LSCC $^{\mathrm{W}}$ versus $\mathrm{LB}(\mathrm{p}<0.0001, \mathrm{r}=1.000)$

Wilcoxon matched-pairs signed-ranks test: $\mathrm{p}=0.1085$

$\mathrm{LSCC}^{\mathrm{S}}=$ in situ laryngeal carcinoma, $\mathrm{LSCC}^{\mathrm{WT}}=$ invasive laryngeal carcinoma without metastases, $\mathrm{LSCC}^{\mathrm{W}}=$ invasive laryngeal carcinoma with metastases, $\mathrm{LB}=$ cervical lymph nodes.

Data are reported as mean $(\mathrm{M})$ and standard error of the mean (SEM) 
Table 5 - Expression of galectin-3 classified according to immunolabeling intensity in laryngeal carcinoma stratified according to histological diagnosis

\begin{tabular}{lcc}
\hline & Galectin 3 & \\
\hline & Low Expression & High Expression \\
& $\mathrm{n}(\%)$ & $\mathrm{n}(\%)$ \\
$\mathrm{LSCC}^{\mathrm{S}}(\mathrm{n}=10)$ & $8(80 \%)$ & $2(20 \%)$ \\
$\mathrm{LSCC}^{\mathrm{WT}}(\mathrm{n}=27)$ & $6(22.2 \%)$ & $21(77.7 \%)$ \\
$\mathrm{LSCC}^{\mathrm{W}}(\mathrm{n}=28)$ & $4(14.28 \%)$ & $24(84.71 \%)$ \\
$\mathrm{LB}(\mathrm{n}=28)$ & $2(7.14 \%)$ & $26(92.85 \%)$
\end{tabular}

Fisher's Exact Test: p-values $\operatorname{LSCC}^{\mathrm{S}}$ versus $\operatorname{LSCC}^{\mathrm{WT}}(\mathrm{p}=0.0023), \mathrm{LSCC}^{\mathrm{S}}$ versus $\mathrm{LSCC}^{\mathrm{W}}(\mathrm{p}=0.0004)$, $\operatorname{LSCC}^{\mathrm{WT}}$ versus LSCC ${ }^{\mathrm{W}}(\mathrm{p}=0.5027)$ and $\mathrm{LSCC}^{\mathrm{W}}$ versus LB $(\mathrm{p}>0.6695)$.

$\mathrm{LSCC}^{\mathrm{S}}=$ in situ laryngeal carcinoma, $\mathrm{LSCC}^{\mathrm{WT}}=$ invasive laryngeal carcinoma without metastases, $\mathrm{LSCC}^{\mathrm{W}}=$ invasive laryngeal carcinoma with metastases, $\mathrm{LB}=$ cervical lymph nodes. 